\title{
Die Kehrseite des Diskurses. Zur Un(mit)teilbarkeit des Individuums bei Augustinus
}

\author{
Sed ne rationi nostrae adversentur, \\ qua dictum est mutato subiecto omne, \\ quod in subiecto est, necessario mutari, \\ videndum est \\ Augustinus, De inmortalitate animae 8
}

„Nichts scheint mir sichrer als das nie Gewisse, nichts sonnenklarer als die schwarze Nacht. Nur das ist mein, was ich betrübt vermisse, und was ich liebte, hab ich umgebracht."

François Villon, Die Ballade von den Vogelfreien

Trotzdem wird vom Individuum geschrieben werden. Attributiv und in all seiner Vorläufigkeit. Eine Diachronie und Diatopie also von vornherein, die sich symptomatisch ins Zentrum des Besprochenen schiebt: das Ego. Das zelebrative Ego, auf das alles verschoben werden kann, steht im Blick, als ein Fragment allerdings, von jeder Perspektive aus besehen, ein Symbol, das für jedes Subjekt insofern gleich ist, als niemand darüber verfügt. Als es niemand in seiner Ent-legenheit aufspüren kann. „Kein Wunder ist es, wenn sich meinem Ich fern zeigt, was ich nicht bin. Was aber ist mir näher als mein Ich? Und siehe, da wird schon diese meine Kraft Gedächtnis nicht von mir begriffen, ohne die ich doch mich selbst nicht einmal nennen könnte. " ${ }^{\text {E1 }}$ Es wird trotzdem vom Individuum geschrieben werden, obwohl - oder gerade weil - es sich in Unbeschreibbarkeit entzieht und sich hinter seinen Selbst-Schreibungen tarnt. Das Paradoxale begleitet also durch den Text.

Sich an der Brüchigkeit (auto)biographischer Worte zu orientieren, erlaubt allein Skizzenhaftes - einem Faden zu folgen, der sich mehr und mehr ins Dunkel verliert, Text(ge)schichten, die sich mithilfe einer Archäologie des Wortes keineswegs nahbarer zeigen, sondern höchstens lesbarer - symptomatischer. Die Figur ist dabei nicht nur multidimensional, sondern auch unerforschbar, und vermag daher nichts anderes als Reflexionsprozesse auszulösen. Es mag also getrost als Anachronismus gelten, sich der subjektiven Disposivität eines spätantiken Autobiographen zu stellen, sich der ornamentalen Eloquenz anzuvertrauen, die er entfaltet, um die Phänomene seines paradoxalen Ichs zu schreiben. Denn - dies dürfte Augustinus erkannt haben - es ist die Sprache allein, die Selbst-Konstruktion und Selbst-Dekonstruktion zu begründen vermag. Das Subjekt, durch diskursive Praktiken angehalten, sich in ein Verhältnis zur Sprache einerseits und zu sich selbst andererseits zu stellen, ist das Ergebnis von Selbst-Techniken. Das Wahr-Sprechen, das Sich-in-Wahrheit-Sprechen, die confessio ist in der neuplatonisch geprägten augustinischen Perspektive der Garant des Selbstbezuges des Einzelnen, der Möglichkeit des Aufsammelns partikulärer Icherfahrungen. ${ }^{2}$ Denn vor allem eines war schon das mittelalterliche Individuum nicht: un(mit)teilbar.

${ }^{1}$ Augustinus, Confessionum libri tredecim X, 16, 25 (ed. Luc Verheijen, CC SL 27, 1, 1, Turnhout 1981) 167f.: Non ita mirum, si a me longe est quidquid ego non sum. Quid autem propinquius me ipso mihi? Et ecce memoriae meae vis non conprehenditur a me, cum ipsum me non dicam praeter illam? Die Arbeit ist Teil des vom Fonds zur Förderung der wissenschaftlichen Forschung (www. fwf.ac.at) an Univ.-Prof. Dr. Walter Pohl verliehenen Wittgenstein-Preises, der das Projekt „Ethnische Identitäten im frühmittelalterlichen Europa“" ermöglicht (www.oeaw.ac.at/gema/wittg_pro/wittg_pro.htm).

${ }^{2}$ Z.B. Augustinus, Confessiones X, 21, 30-24, 35, ed. Verheijen 171-174. Vgl. Charles Taylor, Sources of the Self. The Making of the Modern Identity (Cambridge 1994); Peter von Moos, Unverwechselbarkeit. Persönliche Identität und Identifikation in der 
Dabei steht Augustinus allerdings nicht am Beginn einer als kontinuierlichen Genese der permanenten Selbstaffirmation verstandenen Geschichte des Subjekts des modernen Menschen. Nichts ist immer schon brüchiger gewesen als die Komposition(en) des Ich. In seinen Confessiones entwirft Augustinus nicht das Modell moderner fraktaler Ego-Konzeptionen. Vielmehr konstruiert er ein Offenbarungs-Ich, ein Revelations-Ich: das eschatologisches Element hat sich in einem epistemischen Bruch in der Aufklärung ${ }^{3}$ vom Kollektiv ins Individuum verlegt, sodaß ein Zugriff auf die Ich-Konzeptionen zur Zeit des Augustinus zumindest gebrochen scheint. Das Ich zeigt sich allerdings als Symptom - im Lacanschen Sinn - als die Kehrseite eines Diskurses.

Und dennoch wurde Augustinus manchmal als das erste moderne Individuum bezeichnet, als einer, der zwischen Antike und Moderne, der alten und der neuen Welt stand, ${ }^{4}$ was angesichts seiner Bedeutung innerhalb der christlichen Kirche im Nordafrika des 5. Jahrhunderts nicht ganz von der Hand zu weisen ist. Schon seinen Zeitgenossen galt er als der bekannteste Bischof, seine Reden waren berühmt, seine Briefe wurden in der gesamten lateinischen Welt gelesen, seine Bücher über die christliche Lehre und Rhetorik, in denen er Bildungsgut und Philosophie der Antike adaptierte, hatten großen Einfluß. ${ }^{5}$ Seine Kontroversen mit religiöspolitischen Gruppen wie den Manichäern oder Donatisten prägten die frühe Dogmatik und Kirchengeschichte ebenso wie das soziale Bild der lateinischen Gesellschaft. ${ }^{6}$

Vormoderne (Köln 2004); Manfred Sommer, Zur Formierung der Autobiographie aus Selbstverteidigung und Selbstsuche (Stoa und Augustinus), in: Identität, ed. Odo Marquard/Karlheinz Stierle (Poetik und Hermeneutik 8, München 1979) 699-708; Philip Cary, Augustine's Invention of the Inner Self. The Legacy of a Christian Platonist (Oxford/New York 2000); Therese Fuhrer, Das erzählte Ich: Subjektivität und Authentizität in Confessiones 10, in: Selbsterkenntnis und Gottsuche. Augustinus: Confessiones 10, ed. Norbert Fischer/Dieter Hattrup (Paderborn/München/Wien/Zürich 2007) 41-56.

3 Siehe dazu Michel Foucault, L'archéologie du savoir (Paris 1969) [dt. Übers.: Archäologie des Wissens (Frankfurt am Main $\left.\left.{ }^{13} 2002\right)\right]$.

${ }^{4}$ Vgl. dazu die ausgezeichneten Biographien: Peter Brown, Augustine of Hippo. A Biography (London 1976); [dt. Übers.: Augustinus von Hippo. Biographie (Frankfurt am Main 2000)]; James J. O’Donnell, Augustine. A New Biography (New York 2006); vgl. Peter Brown, Augustine and Sexuality (Berkeley 1983); Robert A. Markus, Saeculum: History and Society in the Theology of St. Augustine (Cambridge 1970); Kurt Flasch, Augustin. Einführung in sein Denken (Stuttgart 1980); Paul J. Archambault, Augustine's Confessions: On the uses and limits of psychobiography; in: Collectanea Augustiniana: Augustine, "Second Founder of the Faith", ed. Joseph C. Schnaubelt/Frederick Van Fleteren (New York 1990) 83-99; Johann Mader, Aurelius Augustinus. Philosophie und Christentum (St. Pölten/Wien 1991); Robert A. Markus, Augustine: A Collection of Critical Essays (Garden City 1972); Conrad Leyser, Authority and Asceticism from Augustine to Gregory the Great (Oxford 2000); Andrew Knowles/Pachomios Penkett, Augustinus und seine Welt (Freiburg im Breisgau 2007); Bernhard Zimmermann, Augustinus, Confessiones - eine Autobiographie? Überlegungen zu einem Scheinproblem, in: Antike Autobiographien. Werke - Epochen - Gattungen, ed. Michael Reichel (Europäische Geschichtsdarstellungen 5, Köln/Weimar/Wien 2005) 251-277. Aus der Fülle an Literatur, die zu den im Text berührten augustinischen Themen erschienen ist, kann hier nur eine in äußerstem Maße selektive Auswahl zitiert werden; vgl. die systematische Bibliographie bei: www.augustinus.de.

5 Henri-Irénée Marrou, Augustin und das Ende der antiken Bildung (Paderborn 1981); Etienne Gilson, The Christian Philosophy of Saint Augustine (London 1961); Pierre Courcelle, Die Entdeckung des christlichen Neuplatonismus, in: Zum Augustin-Gespräch der Gegenwart 1, ed. Carl Andresen (Darmstadt 1975) 125-181; Ilsetraut Hadot, Erziehung und Bildung bei Augustin, in: Internationales Symposion über den Stand der Augustinus-Forschung vom 12.-16. April 1987 - Ebsdorfergrund, ed. Cornelius Petrus Mayer/Karl Heinz Chelius (Cassiciacum 39, 1, Würzburg 1989) 99-130; Udo Reinhold Jeck, Aristoteles contra Augustinum. Zur Frage nach dem Verhältnis von Zeit und Seele bei den antiken Aristoteleskommentatoren, im arabischen Aristotelismus und im 13. Jahrhundert (Bochumer Studien zur Philosophie 21, Amsterdam 1994); Christine Mohrmann, Der Schriftsteller Augustin, in: Zum Augustin-Gespräch der Gegenwart 1, ed. Carl Andresen (Darmstadt 1975) 89-121; John J. O'Meara, Augustine and NeoPlatonism, in: Recherches Augustiniennes 1 (Supplement a la Revue des Études Augustiniennes, Paris 1958) 91-111; Ubaldo Ramón Pérez Paoli, Der plotinische Begriff von 'YПO $\Sigma T A \Sigma I \Sigma$ und die augustinische Bestimmung Gottes als Subiectum (Cassiciacum 51, Würzburg 1990); Cornelius Petrus Mayer, Die Confessiones des Aurelius Augustinus. Eine philosophisch-theologische Werbeschrift (Protrepikos) für christliche Spiritualität. Dargestellt vorzüglich im Blick auf Buch X, in: Theologie und Glaube 88 (1998) 285-303; Pierre Hadot/Ursula Brenke, Christlicher Neuplatonismus. Die theologischen Schriften des Marius Victorinus (Zürich/Stuttgart 1967); Leo Sweeney, "Was St. Augustine a Neoplatonist or a Christian?” Old question, new approach, in: Collectanea Augustiniana: Augustine, "Second Founder of the Faith", ed. Joseph C. Schnaubelt/Frederick Van Fleteren (New York 1990) 403-420.

${ }^{6}$ Robert A. Markus, Augustine's Confessions and the controversy with Julian of Eclanum: manichaeism revisited, in: Collectanea Augustiniana. Mélanges Tarsicius Jan Van Bavel, ed. Bernard Bruning/Mathijs Lamberigts/Jozef Van Houtem (Bibliotheca Ephemeridium Theologicarum Lovaniensium 92, B, Leuven 1990) 913-925; Vernon J. Bourke, The body-soul relationship in early Augustine, in: Collectanea Augustiniana: Augustine, "Second Founder of the Faith", ed. Joseph C. Schnaubelt/Frederick Van Fleteren (New York 1990) 435-450; Brian Stock, Augustine. The Reader. Meditation, Self-Knowledge, and the Ethics of Interpretation 
Die Confessiones, in denen Augustinus ein Bekenntnis-Ich entwarf, sind jene textuelle Schnittstelle zwischen einer sozialen Repräsentanz und einem völlig verunsichterten Ego, zwischen einer aus der antiken Vergangenheit drängenden gesellschaftlichen Verantwortung und einer in die Zukunft gedehnten Erwartung christlicher Prägung. ${ }^{7}$ An dieser Schnittstelle werden voluntas und caritas angesiedelt. ${ }^{8}$ Und hier kann die Umkehrung geschehen - die conversio - oder sollte man besser von einer subversio sprechen? ${ }^{9}$ Einer grundsätzlichen, radikalen Umwendung des als Ego verstandenen und so mühsam begriffenen Subjekts? Als der Versuch einer endgültigen Umkehrung des permanenten Mißerfolgs? Womit auch die Einheit des Subjekts als Kriterium aufgelöst werden würde, weil es auf ein Größeres, ein Außerhalb bezogen wäre. Eine Identität jenseits der verbalen Oppositionen, der Subjektivierungen von Gegensätzen, der Kategorien aus dem Universum der Sprache, das Augustinus in Texten wie De magistro oder De doctrina christiana erkundet hat. Zerrissenheit - distentio -, das Fremde bedroht die Identität von Außen. Das Ungewisse, Unzuträgliche schiebt sich in die Homologie des Ego, wobei dies in augustinisch-christlicher Perspektive eine Zukunftsidentität erst ermöglicht. ${ }^{10}$ Allein der Selbst-Verzicht gewährt Identität. Das Scheitern am Ego ist also nicht fakultativ, sondern konstititiv, oder anders formuliert läßt sich ein individuelles Ego nur zum Preis der Entäußerung und Selbstaufgabe halten.

In der augustinischen Perspektive ist die Rhetorik das Dispositiv der Vermittlung von Wissen. ${ }^{11}$ Dabei wird das Wahrheitgemäße mit dem Persuasiven identifiziert: wer wahr spricht, wird überzeugen, besonders wenn er sich selbst zur Sprache bringt. Dieses Zur-Sprache-Bringen ist tatsächlich eine Hin- und Anbringung, eine Projektion auf ein Äußeres, Allgemeines und Übersprachliches: man bringt etwas zur Sprache hin, überträgt es auf sie. Es ist eine Über-Setzung von Un-Sprachlichem ins Sprachliche und wieder zurück. Es ist das innere, von Anfang an übermittelte Wort, dem man sich anvertrauen soll, eine Spur bis an den Anfang der Selbstheit, der spiritus hominis im interpretativen Verhalten zum medicus intimus. ${ }^{12}$ Das Medium, das diesem Vermittlungsprozeß dient, muß daher transparent sein, damit die An-Gleichung an den wahrsprechenden magister interior gelingen kann. ${ }^{13}$

Augustins confessionelles Schreiben ist schonungslose verbale Suche nach dem Subjekt und gleichzeitig seine Auslöschung. Dabei will es verbergen, daß es den Diskurs einem starken Kontrollzwang unterwirft: die Sprache steht unter dem Verdacht, eine Bewegung zu entfalten, die der Kontrolle durch das Subjekt entglei-

(Cambridge-Mass./London 1996) 43-74; Klaus Kienzler, Gott in der Zeit berühren. Eine Auslegung der Confessiones des Augustinus (Würzburg 1998).

${ }^{7}$ Vgl. Kurt Flasch, Was ist Zeit? Augustinus von Hippo. Das XI. Buch der Confessiones. Historisch-philosophische Studie. Text Übersetzung - Kommentar (Frankfurt am Main 1993).

${ }^{8}$ Augustinus, Confessiones X, 29, 40, ed. Verheijen 176.

${ }^{9}$ Karl F. Morrison, Conversion and Text. The Cases of Augustine of Hippo, Herman-Judah, and Constantine Tsatsos (Charlottesville/ London 1992); Cornelius Petrus Mayer, Artikel "Confessio, confiteri”, in: Augustinus-Lexikon 1, 8, ed. Cornelius Petrus Mayer/ Karl Heinz Chelius (Basel/Stuttgart 1994) 1122-1134; Leo C. Ferrari, Saint Augustine's conversion scene: the end of a modern debate?, in: Studia Patristica 22. Papers Presented to the Tenth International Conference on Patristic Studies Held in Oxford 1987. Cappadocian Fathers, Chrysostom and the Greek Contemporaries, Augustine, Donatism and Pelagianism, ed. Elizabeth A. Livingstone (Leuven 1989) 235-250; Paula Fredriksen, Paul and Augustine: conversion narratives, orthodox traditions, and the retrospective self, in: Journal of Theological Studies 37 (1986) 3-34; E. Ann Matter, Conversion(s) in the Confessiones, in: Collectanea Augustiniana: Augustine, "Second Founder of the Faith", ed. Joseph C. Schnaubelt/Frederick Van Fleteren (New York 1990) 21-28; Frederick Van Fleteren, St. Augustine's theory of conversion, in: Collectanea Augustiniana: Augustine, "Second Founder of the Faith”, ed. Joseph C. Schnaubelt/Frederick Van Fleteren (New York 1990) 65-80; Robert J. O'Connell, St. Augustine's Confessions. The Odyssey of Soul (Cambridge 1969); Torsten Krämer, Augustinus zwischen Wahrheit und Lüge. Literarische Tätigkeit als Selbstfindung und Selbsterfindung (Hypomnemata. Untersuchungen zur Antike und zu ihrem Nachleben 170, Göttingen 2007) $115-126$.

${ }_{10}$ Augustinus, Confessiones X, 5, 7, ed. Verheijen 158: Confitear quid de me sciam, confitear et quid de me nesciam, quoniam et quod de me scio, te mihi lucente scio, et quod de me nescio, tamdiu nescio, donec fiant tenebrae meae sicut meridies in vultu tuo.

${ }^{11}$ Jochen Fritz, Ruinen des Selbst. Autobiographisches Schreiben bei Augustinus, Rousseau und Proust (München 2007) 108ff.; Werner Beierwaltes, Deus est veritas. Zur Rezeption des griechischen Wahrheitsbegriffes in der frühchristlichen Theologie, in: Pietas. Festschrift für Bernhard Kötting, ed. Ernst Dassmann/Karl Suso Frank (Jahrbuch für Antike und Christentum Ergänzungsband 8, Münster 1980) 15-29; Christian Tornau, Zwischen Rhetorik und Philosophie. Augustins Argumentationstechnik in De civitate Dei und ihr bildungsgeschichtlicher Hintergrund (Untersuchungen zur antiken Literatur und Geschichte 82, Berlin/New York 2006).

${ }_{12}$ Z.B. Augustinus, Confessiones VIII, 1, 1, ed. Verheijen 113; ebd. X, 3, 3, ed. Verheijen 156: Et unde sciunt, cum a me ipso de me ipso audiunt, an verum dicam, quandoquidem nemo scit hominum, quid agatur in homine, nisi spiritus hominis, qui in ipso est?; in Exegese von 2 Kor 2, 11; ebd. X, 3, 4, ed. Verheijen 156f.

${ }^{13}$ Z.B. Augustinus, Confessiones VII, 9, 13; VII, 10, 16; XIII, 1, 1, ed. Verheijen 101, 103f., 242. 
tet. Mangelhafte Über-Setzungen könnten sich in den Wahrheits-Diskurs einschleichen, besonders da das Subjekt ja selbst Teil dieses Diskurses geworden ist, sich ihm rückhaltslos anheimgestellt und anvertraut hat - die interpretative Auslegung, die explicatio des Ego ist also eine Übersetzung. Diese Projektion wird zu einer Rejektion, in der das Wahr-Sprechen nun das Subjekt und den Subjekt-Text kontrolliert. Was von dort zurückgeworfen wird, ist jenes paradoxale Ich, das sich allein in der Gegenwart/im Inneren erleben, aber nur in Vergangenheit und Zukunft/im Äußeren begreifen kann. ${ }^{14}$ Die gläserne Durchsichtigkeit des Subjekts, des Bekenntnis-Ichs, das man dadurch gewonnen glaubt, verbirgt nichts weniger als sich selbst. Es verwandelt sich in eine „Strategie des Begehrens“". ${ }^{15}$ In der Allegorie der Verwandlung, die das Bekennen ausspricht, wird das Subjekt selbst Teil der Kontrolle des Wahrheits-Diskurses. Das Ego wird als eine rhetorische Konfiguration erkannt - sed tu mutaberis in me. ${ }^{16}$ Sowohl durch die Notwendigkeit seiner Verwandlung als auch durch den destabilen Charakter der metaphorischen Sprache an sich ist das selbstreflexive Bekenntnis-Subjekt bei Augustinus fragil konzipiert. ${ }^{17}, \ldots$ und mir war, als hörte ich aus ferner Höhe Deine Stimme: ,Ich bin das Brot der Starken: wachse, und du wirst mich essen. Und nicht du wirst mich in dich verwandeln wie die Speise für deinen Leib, sondern du wirst in mich gewandelt werden. “"18 Erkenntnis ist grundsätzlich sprachlich strukturiert. Die Deklamation der conversio präsentiert ein poetisches Ich, das sich entlang einer Stilisierung zwischen Vergillektüre und Psalmen- sowie Genesisexegese entwirft. ${ }^{19}$

„Und ich fragte mich: ,Ist denn die Wahrheit nichts, weil sie nicht Ort bei Ort sich durch Räume breitet, nicht durch begrenzte, nicht durch unbegrenzte?' Und Du riefst aus der Ferne: ,Nein! Ich bin es, der Ich bin. ' Und ich hörte es, so wie man mit dem Herzen hört, und fürder war nicht mehr, daß ich noch hätte zweifeln können, und eher hätte ich gezweifelt, daß ich lebe, als daran, daß Wahrheit ist, die am Geschaffenen durch seine Erkenntnis sich schauen läßt." ${ }^{\prime 20}$

Ego erhielt in den augustinischen Texten eine Symbolfunktion und damit eine semantische Verdichtung, die eine Sprache der Differenzen voraussetzt. Ego als Symbol ist bei Augustinus eine Transposition, eine Entstellung des Symbols Gesellschaft und ein Zeichen der Abwesenheit, die eine Sprache des Mangels begleitet. Die Differenz, die sich in das Ich eingenistet hat, wird zum Gegenbild einer als ursprünglich gedachten Einheit, einer Umhüllung im Firmament der Vor-Zeichenhaftigkeit, die sich entfaltet. Aus diesem auch als Zentrum des Ich gedachten, spekulativen Innen kommt die beinahe unzugängliche Ruhe und Stabilität, die der Zerrissenheit des äußeren Ich widerstrebt. Im differenten Subjektsein hat sich ein Unbehagen in sich Selbst/in Sich selbst eingenistet: dieses Unbehagen ist ein Sozio-Graph. Es beschreibt den Abstand des Einzelnen zur utopischen, perfektionierten, eschatologischen Gesellschaft, das teleologische Ziel jener societas permixta, der sich der Rhetor - grundsätzlich in einer kommunikativen Situation - als exemplum göttlicher Wirkung anempfiehlt. ${ }^{21}$ Individuell konzipierte Identitätsentwürfe gewinnen in dieser Sicht den Charakter von Identitäts-Vorwürfen.

${ }^{14}$ Augustinus, Confessiones VII, 10, 16; X, 6, 8-14, 21; XI, ed. Verheijen 103f., 158-166, 194-216.

15 Jean Baudrillard, Das Andere selbst: Habilitation (Wien 1987) 13.

${ }_{16}$ Augustinus, Confessiones VII, 10, 16, ed. Verheijen 103f.

${ }^{17}$ Augustinus, Confessiones I, 1, 1-3, 3; I, 5, 6, ed. Verheijen 1f., 3; ders., De inmortalitate animae liber unus 5, 8; 8, 13-15 (ed. Wolfgang Hörmann, CSEL 89, 1, 4, Wien 1986) 99-128, hier 108f., 114-117.

${ }_{18}$ Augustinus, Confessiones VII, 10, 16, ed. Verheijen 103f.: ... tamquam audirem vocem tuam de excelso: „Cibus sum grandium: cresce et manducabis me. Nec tu me in te mutabis sicut cibum carnis tuae, sed tu mutaberis in me. "

${ }^{19}$ Vgl. dazu Gerhard Anselm Müller, Formen und Funktionen der Vergilzitate bei Augustinus von Hippo. Formen und Funktionen der Zitate und Anspielungen (Studien zur Geschichte und Kultur des Altertums N.F. 1. Reihe 18, Paderborn/München/Wien/Zürich 2003) 182-209; Georg Nicolaus Knauer, Psalmenzitate in Augustins Konfessionen (Göttingen 1955).

${ }^{20}$ Augustinus, Confessiones VII, 10, 16, ed. Verheijen 104: ... et dixi: „, Numquid nihil est veritas, quoniam neque per finita neque per infinita locorum spatia diffusa est? “ Et clamasti de longinquo: „Immo vero ego sum qui sum“. Et audivi, sicut auditur in corde, et non erat prorsus, unde dubitarem faciliusque dubitarem vivere me quam non esse veritatem, quae per ea, quae facta sunt, intellecta conspicitur. Vgl. ebd. VII, 17, 23, ed. Verheijen 107.

${ }^{21}$ Vgl. Hildegund Müller, Zur Erzähltechnik der Confessiones. Eine Detailbeobachtung, in: Le Confessioni di Agostino (402-2002). Bilancio e prospettive. XXXI Incontro di studiosi dell'antichità cristiana, Roma, 2-4 maggio 2002 (Studia Ephemeridis Augustinianum 85, Roma 2003) 79-87; Susanne Müller-Abels, Ego cum deliberabam, ut iam servirem domino meo (conf. VIII, 10, 23). Der Einfluß der Confessiones des Augustinus auf conversi im 5. Jahrhundert am Beispiel des Ruricius von Limoges, in: Le Confessioni di Agostino (402-2002): Bilancio e prospettive. XXXI Incontro di studiosi dell'antichità cristiana, Roma, 2-4 maggio 2002 (Studia Ephemeridis Augustinianum 85, Roma 2003) 589-596; siehe den Beitrag von Kate Cooper in diesem Band. 
Eine deutliche Metapher des Begehrens ist der *sexus als das Symbol der Differenzen, das sich den verschiedenen Codierungen von Geschlecht anbietet. ${ }^{22}$ Der Begriff markiert ein diskursives Dispositiv deutlich markierbarer Differenz, das, weit mehr als nur auf der Ebene des Körpers, als Akzidenz der Schöpfung gedacht wird. Er wird auf den Ebenen der Re-präsentationen von Geschlecht ebenso sichtbar wie in den Umschreibungen der angrenzenden Praktiken, wie etwa dem ethischen Diskurs der christlichen caritas oder der Dynamik der episteme. ${ }^{23}$ Das peccatum originale in der augustinischen Theologie ist in dieser Hinsicht nicht auf die körperliche Differenz zu beziehen, sondern läßt sich als Markierungslinie der Dramatik menschlichen Erkennens im Verhältnis zum göttlichen Wissen interpretieren, die ein Riß zu trennen begann. In diesem Rahmen wird es unmöglich sein, die komplexen dialektischen Verhältnisse von memoria, intellectus, voluntas (mens, anima, corpus) zu erläutern und auf die Konnotationsebenen der in seinen Texten vielfach gespiegelten und als Abbild verstandenen Triaden einzugehen. ${ }^{24}$ Hier sollen vor allem die Diskontinuitäten und die Paradoxa skizziert werden, die Augustinus zufolge das Begehren im Subjekt auslösen. Allein schon die Koexistenz komplexer pluraler Identitäten in einem Kollektiv, das sich eine trinitarische Hypostase vorzustellen versucht, die aus jeweils autonomen Identitäten besteht, ist allerdings schwer zu leugnen. In dieser Hinsicht ist das, was uns von Augustinus erhalten ist, tatsächlich modern, weil es bis heute Interpretationen provoziert.

\section{CONVERSIO - SUBVERSIO}

Was ist in diesem Zusammenhang das Provokante an Augustinus' Denken? Er scheint zunächst erkannt zu haben, daß am Beginn des menschlichen Daseins das Zeichen als das Unterscheidende, Kategorisierende steht, die Sprache des Subjekts, das sich interpretativ (exegetisch) das Universum der Zeichen einverleibt. ${ }^{25}$ Damit ist aber ein grundsätzliches Paradoxon verbunden: der Anspruch, die Zeichen zu fordern und sie sich zurechtzulegen, widerspricht dem grundsätzlichen Anspruch, den der Mensch vom Unendlichen her erfährt, ein Angesprochensein. Im augustinischen pessimistischen Menschenbild tritt eine deutliche Differenz zwischen der radikalen Heteronomie des Menschen und der unendlichen Ferne Gottes entgegen. Dem Einnehmen und Wahrnehmen subjektiver Positionen im Diskurs widerspricht die Annahme einer semantischen

${ }^{22}$ Siehe zuletzt: Mathijs Lamberigts, Some critiques on Augustine's view of sexuality revisited, in: Studia Patristica 33 (1997) 152-161; ders., A critical evaluation of critiques of Augustine's view of sexuality, in: Augustine and His Critiques. Essays in Honour of Gerald Bonner, ed. Robert Dodaro/George Lawless (London/New York 2000) 176-197; Larissa Clarina Seelbach, „Das weibliche Geschlecht ist ja kein Gebrechen ...". Die Frau und ihre Gottebenbildlichkeit bei Augustin (Cassiciacum 50, Würzburg 2002); Christof Müller, Artikel „femina“, in: Augustinus-Lexikon 2 (2002) 1266-1281.

${ }^{23}$ Vgl. Josef Brechtken, Augustinus Doctor Caritatis: sein Liebesbegriff im Widerspruch von Eigennutz und selbstloser Güte im Rahmen der antiken Glückseligkeits-Ethik (Monographien zur philosophischen Forschung 136, Meisenheim am Glan 1975).

${ }^{24}$ Vgl. dazu Johann Kreuzer, Pulchritudo. Zum Erkennen Gottes bei Augustin. Bemerkungen zu den Büchern IX, X und XI der Confessiones (München 1995); Jaroslav Pelikan, Canonica regula: The trinitarian hermeneutics of Augustine, in: Collectanea Augustiniana: Augustine, “Second Founder of the Faith”, ed. Joseph C. Schnaubelt/Frederick Van Fleteren (New York 1990) 329-343; Drago Pintarič, Sprache und Trinität. Semantische Probleme in der Trinitätslehre des Hl. Augustinus (Salzburger Studien zur Philosophie 15, Salzburg 1983); Dale Lindskog, Diagnosis and Dissolution. From Augustine's Picture to Wittgenstein's Picture Theory (Wittgenstein Studien 14, Frankfurt am Main 2007).

${ }^{25}$ Grundlegend zum Zeichenbegriff bei Augustinus: Cornelius Petrus Mayer, Die Zeichen in der geistigen Entwicklung und in der Theologie des jungen Augustinus (Cassiciacum 24, 1, Würzburg 1969); ders., Die Zeichen in der geistigen Entwicklung und in der Theologie Augustins. Die antimanichäische Epoche (Cassiciacum 24, 2, Würzburg 1974); ders., Kenntnis und Bewertung der Zeichen als Voraussetzung der Bibelhermeneutik nach Augustinus, in: Nach den Anfängen fragen. Festschrift Gerhard Dautzenberg zum 60. Geburtstag, ed. Cornelius Petrus Mayer/Karlheinz Müller/Gerhard Schmalenberg (Gießener Schriften zur Theologie und Religionspädagogik 8, Gießen 1994) 719-738; ders., Signifikationshermeneutik im Dienste der Daseinsauslegung. Die Funktion der Verweisungen in den Confessiones X-XIII, in: Augustiniana 24 (1974) 21-74; vgl. Adolf Holl, Die Welt der Zeichen bei Augustin. Religions-phänomenologische Analyse des 13. Buches der Confessiones (Wiener Beiträge zur Theologie 2, Wien 1963); Belford Darrell Jackson, The theory of signs in St. Augustine's De doctrina christiana, in: Revue des Études Augustiniennes 15 (1969) 9-49; Klaus Kahnert, Entmachtung der Zeichen? Augustin über Sprache (Bochumer Studien zur Philosophie 29, Amsterdam 2000); Kurt Smolak, „Sic itaque audiar!“. Zum Phänomen ,Sprache“ in Augustins Confessiones, in: Augustinus 39 (1994) 509-517; Michael Thomas Liske, Gegenstandsbezug durch Zeichen und unmittelbare Wirklichkeitserfahrung in Augustins De magistro, in: Vir bonus dicendi peritus. Festschrift für Alfons Weische zum 65. Geburtstag, ed. Beate Czapla/Thomas Lehmann/ Susanne Liell (Wiesbaden 1997) 271-286. 
Tiefe, eines Grundes, von dem aus die Zeichen reden, eines Firmaments, in das die Worte geheftet wurden. ${ }^{26}$ Dadurch entsteht ein Riß im Selbstbewußtsein, eine distentio animi, wie Augustinus schreibt ${ }^{27}$ - eine Dialektik, in der es zwar um Abgrenzungen geht, aber nur unter dem Aspekt der Auflösung der Differenzen im als Gott benannten sprachlichen Grund. Differenzen wie etwa die von Frau und Mann - oder sollte man schon von Weiblichem und Männlichem sprechen? - sind in diesem Zeichensystem latent, sie haben weder einen festen Platz noch eine fixierte Aussage. ${ }^{28}$ Differenzen sind das notwendig Wahrnehmbare in einem Fluxus von Zeichen, in einem Netz von Gegebenem, Mitgeteiltem, symbolisch Vermitteltem. Das Nichtfestgelegte, das Arbiträre zwischen Signifikant und Signifikat, die semantische Fluktuation macht das Wesen des Symbolischen aus. Es ist ein autonomes Universum, das nicht allmählich entsteht, sondern da ist, wenn der erste Signifikant, die erste Metapher auftaucht, denn ein Signifikant steht nicht allein, er kann nicht allein stehen, sondern verweist notwendigerweise auf andere Signifikanten - wogegen die Sehnsucht nach dem ersten Wort steht.

„Freilich war die Erde in diesem Sinn wüst und leer und ich weiß nicht welch eine Tiefe des Abgrundes, auf der es finster war, weil sie keine Gestalt hatte. Weshalb befahlst du, daß geschrieben würde, daß Finsternis über dem Abgrund war, wenn dieses nicht die Abwesenheit des Lichtes bedeutete? Denn wo wäre Licht, wenn es wäre, wenn es sich nicht erhoben und die Dinge erleuchtet hätte? Wo also das Licht noch nicht war, was war da das Dasein der Finsternis anderes als die Abwesenheit des Lichtes? Finsternis war daher über der Tiefe, weil das Licht nicht darüber war, so wie, wo kein Laut sich hören läßt, Schweigen herrscht. Und was ist, daß dort Schweigen herrscht, anderes, als daß kein Laut hörbar ist?"29

Sobald das Symbol auftaucht, gibt es ein Universum von Symbolen. ${ }^{30}$ Es existiert keine Vor-Zeit des Symbolischen, es gibt keine präexistenten Vorstufen, keine Mittelbarkeit. Die symbolische Ordnung - so klein sie auch in ihrer Relationalität sein mag - impliziert sogleich mit ihrem Auftauchen eine Totalität dessen, was menschlich ist und als Identisches entworfen werden kann bzw. wovon sich das Identische absetzen kann. Sie ist in dem Sinn irreduzibel, als sich ihr das Subjekt in seiner Selbstinvention und -begründung nicht entziehen kann. Die Sprache wird zum mittelbaren Träger von Identität, allerdings in einer zeitlich unmittelbaren (und damit a-chronologischen) Momenthaftigkeit.

„Du aber, Herr, der du immer lebst und in dem nichts stirbt, denn vor dem Anfang der Zeiten und vor allem, was Vorzeit genannt werden kann, bist du, Gott und Herr bist du deiner gesamten Schöpfung, und auf festem Grunde ruhen in dir der Urgrund aller an sich unbeständigen Dinge und alles Wandelbaren unwandelbarer Ursprung ..." ${ }^{\text {"31 }}$

${ }^{26}$ Augustinus, Confessiones XIII, 15, 16-18, ed. Verheijen 250-252.

${ }^{27}$ Z.B.: Augustinus, Confessiones IX, 10, 26, ed. Verheijen 148. Vgl. Norbert Fischer, „Distentio animi“. Ein Symbol der Entflüchtigung des Zeitlichen, in: Die Confessiones des Augustinus von Hippo. Einführung und Interpretation zu den dreizehn Büchern, ed. Norbert Fischer/Cornelius Petrus Mayer (Freiburg/Basel/Wien 1998) 489-552.

${ }^{28}$ Richard Corradini, Zeit und Text. Studien zum tempus-Begriff des Augustinus (Veröffentlichungen des Instituts für Österreichische Geschichtsforschung 33, Wien 1997) 113-159.

29 Augustinus, Confessiones XII, 3, 3, ed. Verheijen 217f.: Et nimirum haec terra erat invisibilis et inconposita et nescio qua profunditas abyssi, super quam non erat lux, quia nulla species erat illi: unde iussisti, ut scriberetur, quod tenebrae erant super abyssum; quid aliud quam lucis absentia? Ubi enim lux esset, si esset, nisi super esset eminendo et inlustrando? Ubi ergo lux nondum erat, quid erat adesse tenebras nisi abesse lucem? Super itaque erant tenebrae, quia super lux aberat, sicut sonus ubi non est, silentium est. Et quid est esse ibi silentium nisi sonum ibi non esse?

${ }_{30}$ Jacques Lacan, Das Seminar 2. Das Ich in der Theorie Freuds und in der Technik der Psychoanalyse (Olten/Freiburg 1980) bes. 42-58; vgl. Umberto Eco, Zeichen. Einführung in einen Begriff und seine Geschichte (Frankfurt am Main 1977); Slavoj Žižek, Die Tücke des Subjekts (Frankfurt am Main 2001) 122-125; Mayer, Zeichen 1 und 2; ders., Kenntnis 719-738; Robert A. Markus, Signs and Meanings: World and Text in Ancient Christianity (Liverpool 1996); ders., Signs, Communication, and Communities in Augustine's De doctrina christiana, in: De doctrina christiana. A Classic of Western Culture, ed. Duane W.H. Arnold/Pamela Bright (Notre Dame/London 1995) 97-108; Ulrich Wienbruch, „Signum“, „significatio“ und „,illuminatio“ bei Augustin, in: Der Begriff der Repraesentatio im Mittelalter. Stellvertretung, Symbol, Zeichen, Bild, ed. Albert Zimmermann (Miscellanea Mediaevalia. Veröffentlichungen des Thomas-Instituts der Universität zu Köln 8, Berlin/New York 1971); Walter Magass, Claritas versus obscuritas. Semiotische Bemerkungen zum Wechsel der Zeicheninventare in den Confessiones des Augustin (Conf. XIII, XV, 18), in: Linguistica Biblica 48 (1980) 7-18; Philip Burton, Language in the Confessions of Augustine (Oxford 2007).

${ }_{31}$ Augustinus, Confessiones I, 6, 9, ed. Verheijen 4: Tu autem, Domine, qui et semper vivis et nihil moritur in te, quoniam ante primordia saeculorum et ante omne, quod vel ante dici potest, tu es et Deus es Dominusque omnium, quae creasti, et apud te rerum omnium instabilium stant causae et rerum omnium mutabilium inmutabiles manent origines ... 
Diese Charakterisierungen des Symbolischen unterstreichen deutlich die Heteronomie, das Ausgesetztsein des Subjektes. Das grundsätzliche Problem dabei ist also das des doppelten Anspruchs, wie es kurz skizziert wurde. In den Confessiones wird beschrieben, wie durch die Hereinnahme des Anspruchs in die Problematik der Differenzierungen eine Spaltung in die Bedürfnisse hineinkommt, die zwar am Ursprung des Subjekts stehen sollen, die aber durch die sprachliche Performanz hindurchmüssen.

„Bin ich nicht aus der Kindheit auf dem Wege zu meinem jetzigen Lebensalter in das Knabenalter gelangt, oder besser gesagt: kam es nicht in mich und folgte meiner Kindheit. Doch jene ist nicht vergangen; wohin sollte sie auch gehen: Und doch war sie nicht mehr. Denn nicht mehr war ich ein unmündiges Kind, sondern ein Knabe, der Sprache kundig. Ich erinnere mich noch daran, und woher ich die Sprache lernte, erfuhr ich nachher. Denn es unterrichteten mich nicht Erwachsene, indem sie mir nach einem bestimmten klar durchdachten Lehrplan Worte mitteilten, wie bald nachher die Buchstaben, sondern ich erlernte es selbst kraft des Geistes, den du, mein Gott, mir gegeben hast, wenn ich mit Seufzen und allerlei Tönen und Gebärden die Gefühle, die mein Herz empfand, ausdrücken wollte, damit man meinem Willen nachkäme; ..."32

Doch die sprachliche Performanz hinterläßt die Spur der Undeutlichkeit, sodaß am Anfang der Erfahrung des Sprachlichen die Polysemie miteingebettet wird. Der Sprache eignet damit aber auch Vor- und Außersprachlichkeit - die Sprache ist primär nicht diskursiv und kann nicht auf ein den Sinn durcheilendes Zeichensystem reduziert werden. Sprache und Bedeutung sind nicht von vornherein aufeinander bezogen, ihre Beziehung ist keine natürlich gegebene, sondern ist in ihrem Verweischarakter arbiträr, unpräsentisch und paradox. Die Fächerung von Signifikant und Signifikat setzt das Differenz-Denken frei. Es besteht innerhalb der symbolischen Ordnung keine Identität durch Repräsentanz, sodaß etwa ein Ding nur eine Entsprechung eines Zeichens wäre. Es besteht innerhalb des Systems der Signifikanten durch Differenz. Der semantische Prozeß ist endlos, da er sich aus immer neuen Signifikantenketten zusammensetzt und allein aus den Verschiebungen, den differenten Markierungen, Neues entstehen kann. Sinn ist somit ein Produkt der Anwendung von Sprache, und nicht deren Ursache und Ursprung. Wobei an diesem Punkt unwillkürlich der unüberbrückbare Widerstand der Abstraktion einsetzt, da die Theoretisierung des Zeichens selbst auf Zeichenprozesse zurückgreifen muß, im Moment des Zugriffs aber irritierenderweise seine Identität mit sich verschiebt, aufschiebt, deplaziert. In dieser Bewegung und mit derselben Arbitrarität wird auch das Ich verschoben, das sich als Dokument des Sprechens der Sprache anheimstellt. Die Auseinanderlegung, die durch die Unpräsenz und Arbitrarität des Zeichens geschieht, ermöglicht dem Ich also bloß Perspektivisches, aber kein präsentes Wissen.

„... und ich war nicht imstande, alles, was ich wollte, zu äußern, und sprach mir zuvor stillinnerlich die Worte vor im Gedächtnis; benannte man irgendeinen Gegenstand und wandte man sich bei dem Wort danach, so bemerkte ich es und behielt es bei mir, daß das Ding von ihnen benannt werde, welches sie aussprachen, wenn sie es zeigen wollten. $\mathrm{Da}$ man aber dies damit bezweckte, erhellte aus der Bewegung des Körpers, gleichsam die Universalnatursprache für alle Völker; durch das Mienen- und Augenspiel und die Tätigkeit der übrigen Glieder und durch den Klang der Stimme, welcher anzeigt, was die Seele wünscht und begehrt, was sie verwirft und meidet. So begriff ich allmählich die Worte in ihrer mannigfaltigen Bedeutung, in ihrer verschiedenen Stellung und bei ihrem häufigen Gebrauche, welche Dinge die Worte bezeichneten, und sprach durch sie, da meine Mutter sich bereits an diese Ausdrucksweise gewöhnt hatte, meine Wünsche aus. So bin ich mit denen, unter welchen ich lebte, in eine Gemeinschaft hinsichtlich der Bezeichnung der Willensäußerungen getreten und schritt weiter hinein in die Stürme des gesellschaftlichen Lebens, doch noch abhängig von der Autorität der Eltern und vom Willen Erwachsener." ${ }^{\text {"33 }}$

${ }^{32}$ Augustinus, Confessiones I, 8, 13, ed. Verheijen 7: Nonne ab infantia huc pergens veni in pueritiam? Vel potius ipsa in me venit et successit infantiae? Nec discessit illa: quo enim abiit? Et tamen iam non erat. Non enim eram infans, qui non farer, sed iam puer loquens eram; et memini hoc, et unde loqui didiceram, post adverti. Non enim docebant me maiores homines, praebentes mihi verba certo aliquo ordine doctrinae sicut paulo post litteras, sed ego ipse mente, quam dedisti mihi, Deus meus, cum gemitibus et vocibus variis et variis membrorum motibus edere vellem sensa cordis mei, ut voluntati pareretur, ... Vgl. Andrés G. Niño, The restoration of the adult self in the Confessions, in: Congresso Internazionale su S. Agostino nel XVI centenario della conversione. Roma 15-20 settembre 1986, Atti 2 (Studia Ephemeridis "Augustinianum" 25, Roma 1987) 105-129, hier 110ff.; Eric Robertson Dodds, Pagan and Christian in an Age of Anxiety: Some Aspects of Religious Experience from Marcus Aurelius to Constantine (Cambridge 1965).

${ }_{33}$ Augustinus, Confessiones I, 8, 13, ed. Verheijen 7f.: ... nec valerem quae volebam omnia nec quibus volebam omnibus. Pensebam memoria: cum ipsi appellabant rem aliquam et cum secundum eam vocem corpus ad aliquid movebant, videbam et tenebam hoc ab eis vocari rem illam, quod sonabant, cum eam vellent ostendere. Hoc autem eos velle, ex motu corporis aperiebatur, tamquam 
Die Bedürfnisse stehen in einer Abhängigkeit zum Universum der Sprache in der Weise, daß sie durch seine Hilfe eine Übersetzung und damit Differenzierung erfahren. Die Bedürfnisse erscheinen nun auf der Ebene des Willens, des Begehrens. Ich-Fragmentierungen sind unvermeidbar, um die Imagination der Unversehrtheit der Seele/Identität aufrechtzuerhalten. Die Sprache des Organismus wird im Zuge dieses imaginären Prozesses zu einem Introjekt widriger Emotionen - das Ego kann als Geste enttarnt werden.

„So wird auch unsere Rede erst durch tönende, aufeinanderfolgende Zeichen gebildet. Denn die Rede wird zu keinem Ganzen, wenn nicht das einzelne Wort verklungen, wenn es seine Rolle hat hören lassen, damit nun ein anderes ihm folge ... nicht mehr möge meine Seele sich an die Zeichen hängen mit der Glut der Liebe durch die körperlichen Sinne.

Denn die Dinge gehen dahin, wohin sie seit dem Entstehen gingen, dem Nichtsein entgegen, und sie zerfleischen die Seele mit verderblichem Begehren, weil sie in dem nur sein will und zu ruhen begehrt, was sie liebt." ${ }^{\text {"34 }}$

Hier liegt eine der zentralen Schnittstellen im augustinischen Denken: aus dem Begehren wird das Unendliche teilweise herausgenommen, es wird quasi säkularisiert und hysterisiert. Das Begehren, der *sexus wird zu einer sinnlosen Leidenschaft, die der sapientia und dem intellectus im Weg steht. Die Funktion des Begehrens mit ihrem besitzergreifenden Charakter ist zunächst die Normalität schlechthin, sie ist den Zufällen der Geschichte des Subjekts ausgeliefert - dies bildet den historischen Grundtenor der Confessiones. In einer bestimmten Weise inkludiert dies das Trauma - in Augustinus' Fall in Person seiner Mutter Monnica. Das Spiel mit dem Anderen, die Inszenierung des Willens beherrschte Monnica offenbar bis zur Verleugnung. Als Augustinus im Jahr 375 nach Thagaste zurückkehrte, um öffentlich die manichäische Lehre zu verkünden, verbot ihm seine Mutter das Haus. Mehr noch, sie weinte um ihn „mehr, als Mütter Leichname beweinen.“35

Der direkte Referent des Weinens war zudem nicht er selbst, sondern Gott, der Grund der Sprache. Eine fast unüberbrückbare Spannung wird damit aufgebaut, die - auch rein textuell - nur durch eine permanente Selbstzurücknahme und Selbstbeschuldigung aufrechterhalten werden kann - oder anders formuliert, die Repräsentanz einer Autorität, eines gesellschaftlichen Rollenbildes: das bewegliche, konvertierende Ego, das beschämende Mitleid, die Autorität, die sich um ein unerreichbares Anderes drehen. Jacques Lacan schreibt: „Das Begehren des Menschen gewinnt in der Tat recht einfach Gestalt als Begehren des Anderen, zunächst aber so, daß es lediglich eine subjektive Opazität bewahrt, in der es das Bedürfnis repräsentiert.“" ${ }^{36}$ Und, auf die augustinische Rollenverteilung bezogen, noch präziser lesbar: „Gehen wir aus von der Auffassung des Anderen als Ort des Signifikanten. Keine Aussage von Autorität kann hier anders garantiert sein als in ihrem Aussagen selbst, vergeblich würde sie ihre Garantien in einem anderen Signifikanten suchen, der unter keinen Umständen anderswo erscheint als an diesem Ort. Es gibt keine Metasprache, die man sprechen könnte, oder aphoristischer: Es gibt keinen Anderen des Anderen. “37

verbis naturalibus omnium gentium, quae fiunt vultu et nutu oculorum certerorumque membrorum actu et sonitu vocis indicante affectionem animi in petendis, habendis, reiciendis fugiendisve rebus. Ita verba in variis sententiis locis suis posita et crebro audita quarum rerum signa essent paulatim colligebam measque iam voluntates, edomito in eis signis ore, per haec enuntiabam. Sic cum his, inter quos eram, voluntatum enuntiandarum signa conmunicavi; et vitae humanae procellosam societatem altius ingressus sum, pendens ex parentum auctoritate nutuque maiorum hominum.

${ }^{34}$ Augustinus, Confessiones IV, 10, 15, ed. Verheijen 48: Ecce sic peragitur et sermo noster per signa sonantia. Non enim erit totus sermo, si unum verbum non decedat, cum sonuerit partes suas, ut succedat aliud. Laudet te ex illis anima mea, Deus, creator omnium, sed non eis infigatur glutine amore per sensus corporis. Eunt enim quo ibant, ut non sint, et conscindunt eam desideriis pestilentiosis, quoniam ipso esse vult et requiescere amat in eis, quae amat. Vgl. Hannah Arendt, Der Liebesbegriff bei Augustin. Versuch einer philosophischen Interpretation (Heidelberg 1928, Frankfurt am Main 22003) 29f.; Johannes van Oort, Augustine on sexual concupiscence and original sin, in: Studia patristica 22 (1987) 382-386; The Hunger of the Heart. Reflections on the Confessions of Augustine, ed. Donald Capps/James E. Dittes (Monographies of the Society for the Scientific Study of Religion, University of Connecticut 8, West Lafayette 1990); William S. Babcock, Augustine and the spirituality of desire, in: Augustinian Studies 25 (1994) 179-199; Richard Corradini, Das Dilemma des Willens. Tempus, memoria und voluntas als Symbole der Differenz bei Augustinus, in: Zeit und Geschichte. Kulturgeschichtliche Perspektiven, ed. Erhard Chvojka/Andreas Schwarcz/Klaus Thien (Veröffentlichungen des Instituts für Österreichische Geschichtsforschung 36, Wien 2001) 85-117; Craig J. Neumann de Paulo, Being and Conversion: A Phenomenological Ontology of Radical Restlessness (Ann Arbor 1999).

${ }_{35}$ Augustinus, Confessiones III, 11, 19, ed. Verheijen 37: ... cum pro me fleret ad te mea mater, fidelis tua, amplius quam flent matres corporea funera.

36 Jacques Lacan, Schriften 2 (Olten/Freiburg 1975) 189; vgl. Julia Kristeva, Fremde sind wir uns selbst (Frankfurt am Main 1990) 92ff.; E.J. Hundert, Augustine and the sources of the divided self, in: Political Theory 20 (1992) 86-104, hier 91-95.

${ }^{37}$ Lacan; Schriften 2, 188. 
Monnicas Bedürfnis, ihren Sohn zu kontrollieren und seine hilflosen Versuche, sich gegen diese Vereinnahmung zu wehren, werden an einer weiteren traumatischen Episode deutlich. 382 verließ Augustinus Afrika, um nach Rom zu reisen, doch Monnica wollte ihn nicht alleine fahren lassen.

„Warum aber ich von Karthago nach Rom ging, du wußtest es, Gott, machtest es aber weder mir noch der Mutter kund, die bei meiner Abreise bitterlich weinte und mir bis zum Meer folgte. Ich aber täuschte sie, als sie mich mit Gewalt festhielt, entweder um mich zurückzuhalten oder selbst mit mir zu reisen, und gab vor, bei einem Freund zu bleiben und nicht ohne sie abzufahren, bis ein günstiger Wind die Abfahrt ermögliche ... Und da sie sich weigerte, ohne mich zurückzukehren, überredete ich sie mit Mühe, daß sie in dem unserm Schiff zunächst gelegenen Bauwerk, der Begräbniskapelle des hl. Cyprian, die Nacht verbrächte. In derselben Nacht aber fuhr ich heimlich ab, jene aber blieb zurück in Gebet und Tränen ... Es wehte der Wind, unsere Segel füllten sich und entzogen unseren Augen das Ufer, an dem am Morgen meine Mutter in bitterem Schmerz jammerte und mit Klagen und Seufzen dein Ohr erfüllte, als hättest du ihr Flehen verachtet, da du mich durch meine Gelüste fortreißen würdest, um diesen Gelüsten selbst ein Ende zu machen und meiner Mutter fleischliches Verlangen mit der Geißel gerechten Schmerzes schlugst. In mütterlicher Weise liebte sie, mich immer um sich zu haben, doch viel inniger als andere, und sie wußte nicht, welche Freude du ihr aus meiner Abwesenheit schaffen würdest. Sie wußte es nicht und deshalb weinte und klagte sie, und in jenen Qualen verriet sich in ihr das Erbteil der Eva, wenn sie mit Seufzen suchte, was sie mit Schmerzen geboren." ${ }^{38}$

Eine derart massive Inszenierung wird bei Augustinus zweifelsfrei zu einer Änderung in der Repräsentation der Bedürfnisse geführt haben. Das Begehren des Anderen - dies wird in den Confessiones deutlich - repräsentiert sich als ein doppeltes: als jenes Begehren, das vom Ich ausgeht und sich auf die Objekte ausdehnt, aber auch als jenes, das den Menschen als Anderen begehren läßt. Damit ist es nie bei sich selbst, bedeutet vielmehr Verlust der Kontrolle, Depositionierung und Zerzerrung. „Oder sollte einer die Kunst besitzen, sich selbst zu erschaffen?", frägt Augustinus. ${ }^{39}$ Beinahe angstbesessen wird damit ein Anspruch verteidigt, sich der als konstitutiv gedachten Differenzen zu entledigen. Ist dies zwar grundsätzlich paradox, so läßt sich doch erkennen, daß gerade mit einer solchen Forderung das Begehren in eine epistemologische Funktion eintritt: es wird zum Träger jeglicher Anstrengung nach Wissen, es wird zu einer willensbesetzten Reduktion, einem unbefriedigten Verlangen nach Wissen. In dieser Hinsicht, mit dieser Verschiebung wird die Conversion zur Subversion - mit dem Sprechen über das Sprechen. Warum wählt sich Augustinus in den Confessiones Gott zum Gesprächspartner? Lacan würde vielleicht antworten: „Die Frage nach dem Anderen, die zum Subjekt zurückkommt von dort aus, wo es ein Orakel erwartet - in der Form eines Was willst du? -, ist die Frage, die am allerbesten auf den Weg seines eigenen Begehrens führt. “40 Bei der Interpretation der Zeichen bleibt ein

\footnotetext{
${ }^{38}$ Augustinus, Confessiones V, 8, 15, ed. Verheijen 65: Sed quare hinc abirem et illuc irem, tu sciebas, Deus, nec indicabas mihi nec matri, quae me profectum atrociter planxit, et usque ad mare secuta est. Sed fefelli eam violenter me tenentem, ut aut revocaret aut mecum pergeret, et finxi me amicum nolle deserere, donec vento facto navigaret. Et mentitus sum matri, et illi matri, et evasi; quia et hoc tu dimisisti mihi misericorditer servans me ab aquis maris plenum exsecrandis sordibus usque ad aquam gratiae tuae; qua me abluto siccarentur flumina maternorum oculorum, quibus pro me cotidie tibi rigabat terram sub vultu suo. Et tamen recusanti sine me redire vix persuasi, ut in loco, qui proximus nostrae navi erat, memoria beati Cypriani, maneret ea nocte. Sed ea nocte clanculo ego profectus sum, illa autem non; mansit orando et flendo. Et quid a te petebat, Deus meus, tantis lacrimis, nisi ut navigare me non sineres? Sed alte consulens, et exaudiens cardinem desiderii eius, non curasti quod tunc petebat, ut me faceres quod semper petebat. Flavit ventus et implevit vela nostra, et litus subtraxit aspectibus nostris, in quo mane illa insaniebat dolore et querellis et gemitu implebat aures tuas contemnentis ista, cum et me cupiditatibus raperes ad finiendas ipsas cupiditates, et illius carnale desiderium iusto dolorum flagello vapularet. Amabat enim secum praesentiam meam more matrum, sed multis multo amplius; et nesciebat, quid tu illi gaudiorum facturus esses de absentia mea. Nesciebat, ideo flebat et eiulabat, atque illis cruciatibus arguebatur in ea reliquiarium Evae, cum gemitu quaerens quod cum gemitu pepererat. Et tamen post accusationem fallaciarum et crudelitatis meae, conversa rursum ad deprecandum te pro me abiit ad solita, et ego Romam. Vgl. dazu Dorothea Weber, Adam, Eva und die Schlange: Überlegungen zu Augustins Interpretation des Sündenfalls in De Genesi contra Manichaeos, in: L'etica cristiana nei secoli III e IV: eredità e confronti. 24. Incontro di studiosi dell'antichità cristiana, Roma, 4-6 maggio 1995 (Roma 1996) 401-412; Michaela Zelzer, Zum Bild der Mutter Monnica in den Confessiones des Augustinus, in: In Unum Congregati. Augustiner-Chorherren Jahrbuch 52 (2005) 17-23.

${ }^{39}$ Augustinus, Confessiones I, 6, 10, ed. Verheijen 5: An quisquam se faciendi erit artifex?

${ }^{40}$ Lacan, Schriften 2, 190. Vgl. Reinhart Herzog, Non in sua voce - Augustins Gespräch mit Gott in den Confessiones, in: Das Gespräch, ed. Karlheinz Stierle/Rainer Warning (Poetik und Hermeneutik 11, München 1984) 213-250; Charles Kligerman, A psychoanalytical study of the Confessions of St. Augustine, in: Journal of the American Psychoanalytic Association 5 (1957) 469-484; Robert A. Herrera, St. Augustine's Confessions: a prelude to psychoanalytic theory, in: Augustiniana 39 (1989) 462-473; William
} 
uneinholbarer Rest. Die Erfahrung der Differenzen nimmt die Gestalt des Opaken an, das zwar in seiner Struktur aufgedeckt werden muß, das sich aber ständig (in einer Mensch/Gott-Permutation) als Numen/Sakrales in die Uneinholbarkeit entzieht.

Auf dieser abstrakten, sprachlichen Ebene kann das Subjekt sein Begehren anerkennen und ihm Anerkennung verschaffen: es schafft ihm ein Bild, auf dessen Oberfläche (Projektion) es tastend seine Identität sucht. „Wie aber soll ich anrufen ihn, meinen Gott und Herrn? Denn zu mir hinein rufe ich ihn ja, wenn ich ihn anrufe. Wie heißt die Stätte, dahin mein Gott komme zu mir, wohin der Gott komme zu mir, der Himmel und Erde gemacht hat?" ${ }^{* 41}$ Was auf dieser Ebene als subversiv erfahren wird, kann (mit dem Instrument des Gesetzes) untersagt werden. ${ }^{42}$

„... und worin ahmte ich meinen Herrn nach, wenn auch nur in frevelhafter und verkehrter Weise? War es die Lust, dem Gesetz zuwiderzuhandeln, wenigstens durch Betrug, weil ich mit meinem menschlichen Vermögen die dem Gebundenen mangelnde Freiheit durch strafloses Tun strafbarer Handlungen nicht nachahmen und so ein dunkles Zerrbild deiner Allmacht geben konnte? Es ist jener Knecht, der seinen Herrn verließ, um dem Schatten zu folgen." ${ }^{\text {"43 }}$

Conversion und Subversion liegen enger beinander, allein in der Conversion schwingt die Hysterie (des Bezeichnens), in der Subversion die Differenz (des Bezeichneten) mit. Die Conversion wird als eine Rückkehr zum ursprünglichen Bild/Abbild-Verhältnis empfunden, von dem einen die Zeit getrennt hat. ${ }^{44}$ In dieser Hinsicht eignet ihr etwas Apokatastatisches: Die Ausrichtung des Subjekts auf das Ursprungsprojekt und die damit verbundene Distanzierung von der eigenen personalen Vergangenheit ist gleichermaßen seine Ausrichtung auf die Zukunft. Die conversio ist ein sich der Stabilität Entziehendes, ein Übergang, eine Zwischenwelt, Zwischengestalt. Sie markiert einen Punkt der Umkehr, ein paradigmatisches ,Jetzt“, das zur wesentlichen Identitätsbestimmung beiträgt.

„Da ich ein Jüngling war, flammte auch in mir die Begierde, mich zu sättigen in höllischen Genüssen, und so gab ich mich in wechselnden und lichtscheuen Liebesgenüssen der Verwilderung preis. Und mein Leib verzehrte sich und ich verfiel vor deinen Augen, während ich mir gefiel und den Menschen zu gefallen strebte."“45

H.C. Frend, The family of Augustine: a microcosm of religious change in North Africa, in: Congresso Internazionale su S. Agostino nel XVI centenario della conversione. Roma 15-20 settembre 1986, Atti 1 (Studia Ephemeridis „Augustinianum“ 24, Roma 1987) 135-151; William R. Beers, The Confessions of Augustine: narcissistic elements, in: American Imago 45 (1988) 107-125; Rudolf Braendle/Walter Neidhardt, Lebensgeschichte und Theologie. Ein Beitrag zur psychohistorischen Interpretation Augustins, in: Theologische Zeitschrift 40 (1984) 157-180; Larissa Clarina Seelbach, Psychoanalytische Deutungsversuche zur Persönlichkeit Augustins - Beispiele und Anfragen, in: Freiheit und Gnade in Augustins Confessiones, ed. Norbert Fischer/Dieter Hattrup/ Cornelius Petrus Mayer (Theologie und Glaube 93, Paderborn/München/Wien/Zürich 2003) 240-259; Max Josef Suda, Augustinus in psychohistorischer Sicht, in: Amt und Gemeinde 43, 1 (1992) 1-5; Karlheinz Ruhstorfer, Konversionen. Eine Archäologie der Bestimmung des Menschen bei Foucault, Nietzsche, Augustinus und Paulus (Paderborn/Wien 2004); Rowan Williams, Language, reality and desire in Augustine's De doctrina, in: Journal of Literature and Theology 3 (1989) 138-150.

${ }^{41}$ Augustinus, Confessiones I, 2, 2, ed. Verheijen 1: Et quomodo invocabo Deum meum, Deum et Dominum meum, quoniam utique in me ipsum eum invocabo, cum invocabo eum? Et quis locus est in me, quo veniat in me Deus meus? Quo Deus veniat in me, Deus, qui fecit caelum et terram? Vgl. Jean Greisch, Bekennen - Erzählen - Bezeugen. Diesseits und jenseits der narrativen Identität, in: Irrwege des Lebens. Augustinus: Confessiones 1-6, ed. Norbert Fischer/Dieter Hattrup (Paderborn 2004) 167-180; Mark Vessey, Reading like Angels: Derrida and Augustine on the Book (for a History of Literature), in: Augustine and Postmodernism: Confession and Circumfession, ed. John D. Caputo/Michael J. Scanlon (Bloomington 2005) 173-211.

${ }^{42}$ Jacques Lacan, Das Seminar 1. Freuds technische Schriften (Olten/Freiburg 1978) 235.

${ }^{43}$ Augustinus, Confessiones II, 6, 14, ed. Verheijen 24: ... et in quo Dominum meum vel vitiose atque perverse imitatus sum? An libuit facere contra legem saltem fallacia, quia potentatu non poteram, ut mancam libertatem captivus imitarer, faciendo inpune quod non liceret, tenebrosa omnipotentiae similitudine? Ecce est ille servus fugiens dominum suum et consecutus umbram. Vgl. ebd. XIII, 23, 33-34, ed. Verheijen 261f.

${ }^{44}$ Augustinus, Confessiones X, 6, 8, ed. Verheijen 158f. Vgl. Lawrence J. Daly, Psychohistory and St. Augustine's conversion process. An historiographical critique, in: Augustiniana 28 (1978) 231-254.

${ }^{45}$ Augustinus, Confessiones II, 1, 1, ed. Verheijen 18: Exarsi enim aliquando satiari inferis in adulescentia, et silvescere ausus sum variis et umbrosis amoribus, et contabuit species mea, et conputrui coram oculis tuis, placens mihi et placere cupiens oculis hominum. Vgl. ebd. I, 20, 31, ed. Verheijen 16f.: Eram enim etiam tunc, vivebam atque sentiebam meamque incolumitatem, vestigium secretissimae unitatis, ex qua eram, curae habebam,... 


\section{DIFFERENTIA}

Das Geschlecht steht innerhalb der Praxis der Signifikationen. Sexualität bildet eine signifikante Praxis, die nie nur für sich alleine steht. In den augustinischen Texten begegnet sie häufig unter dem Aspekt der sozialen Differenzen. Geschlecht ist einer der Diskurse, über den sich die komplexe spätantike Gesellschaft formieren konnte. ${ }^{46}$

In Texten wie De ordine oder De trinitate entwickelte Augustinus eine Systematisierung seines Denkens, eine Art Hysterie der Ordnung, in der ein christlicher Diskurs mit dem Anspruch verdichtet wird, eine neue Textur, eine neue Metaphorik, eine neue Sprache zu entwickeln. ${ }^{47}$ In dieser symbolistischen Verdichtung erhalten die Signifikanten häufig eine Überbelastung: das Wortfeld des Begehrens wird beispielsweise - obwohl es vordergründig einer Verschiebung, einer Deplazierung ins Negative nicht entrinnen kann - universalisiert. Einer ähnlichen symbolistischen Verschiebung unterliegt auch die Semantik der Weiblichkeit. Innerhalb der Schöpfungsordnung sind nach Augustinus Frau und Mann gleich, solange sie sich auf den animus, die mens rationalis (die Seele) beziehen. ${ }^{48}$ Erst in Bezug auf die Körper, auf eine Symbolfunktion, nistet sich die Differenz ein. In De genesi ad litteram wird diesbezüglich formuliert:

„Ob Gott nicht im Zusammenhang mit jenen ersten Werken, die er allesamt zugleich erschuf, auch die menschliche Seele erschaffen habe? Zur gegebenen Zeit wäre sie dann den Gliedern des aus Schlamm geformten Körpers eingehaucht worden; eines Körpers freilich, von dem Gott unter den zugleich begründeten Werken den Gedanken ursächlich erschaffen hatte, nach dem erst der menschliche Körper ... zustande kam. Denn richtig verstehen wir das nach seinem Bilde nur in bezug auf die Seele, so wie jenes männlich und weiblich nur in bezug auf den Körper." ${ }^{649}$

Das bedeutet allerdings, daß ein Riß zwischen der äußeren und der inneren Frau besteht, daß die Frau einer grundsätzlichen doppelten Differenz unterliegt: der zum Mann und der zwischen ihrer Seele und ihrem Körper.

Die Entdeckung der Andersartigkeit des anderen Geschlechtes erhält somit einen temporären Aspekt. Das Subjekt tritt damit in die Welt des Symbolischen ein, die sich durch binäre Gegensätze definiert: Frau/Mann, Eltern/Kind, Leben/Tod, Genesis/Apokalypse. Die festgestellte Geschlechterdifferenz beantwortet aber dem Subjekt seine Fragen bezüglich des Unterschieds nicht, d.h. das Symbolische bleibt unvollständig, es erfaßt niemals die ganze Realitätserfahrung, es bleibt ein unausgesprochener, weil unaussprechlicher, in die Sprache nicht eingehender Rest, den Lacan das Reale nennt, also das, was sich dem Symbolischen entzieht. „Doch was war ich noch vor jener Zeit, meine Wonne, mein Gott; war ich überhaupt irgendwo oder irgendwer? Denn ich habe niemanden, der mir darüber etwas sagen könnte, weder Vater noch Mutter vermochten es, weder anderer Erfahrung noch meine eigene Erinnerung (klärten mich darüber auf). “50

Die Konstatierung einer Differenz innerhalb der Identität Frau/Mann/Mensch bestimmt das Wahrheitskriterium beim Sprechen: diese Nicht-Identität wird durch die fundamentale Differenz innerhalb der Sprache gebildet, daß Geschlechterdifferenz in keinen Diskurs adäquat eingeschrieben werden kann. Der sichtbare Unterschied der Geschlechter, der sich dem Sprechen versagt, mündet in diskursive Bemühungen, die Differenz

\footnotetext{
${ }^{46}$ Peter Brown, The Body and Society. Men, Women and Sexual Renunciation in Early Christianity (Suffolk 1990); [dt. Übers.: Die Keuschheit der Engel. Sexuelle Entsagung, Askese und Körperlichkeit am Anfang des Christentums (München/Wien 1991)]; Michel Foucault, Die Sorge um sich. Sexualität und Wahrheit 3 (Frankfurt am Main 21991) 301-307; Margaret R. Miles, Augustine on the Body (American Academy of Religion 31, Missoula 1979).

${ }^{47}$ Peter Brown, Power and Persuasion in Late Antiquity. Toward a Christian Empire (Madison 1992).

48 Augustinus, De trinitate libri quindecim XII, 7, 10 (ed. William J. Mountain, CC SL 50, 16, 1, Turnhout 1968) $364 f$.

49 Augustinus, De genesi ad litteram libri duodecim VII, 24 (ed. Joseph Zycha, CSEL 28, 3, 1, Prag/Wien/Leipzig 1894) 1-435, hier 222f.: Illud ergo videamus, utrum forsitan verum esse possit, quod certe humanae opinioni tolerabilius mihi videtur, Deum in illis primis operibus, quae simul omnia creavit, animam etiam humanam creasse, quam suo tempore membris ex limo formati corporis inspiraret: cuius corporis in illis simul conditis rebus rationem creasse causaliter, secundum quam fieret, cum faciendum esset, corpus humanum. Nam neque illud, quod dictum est ,, ad imaginem suam “, nisi in anima neque illud, quod dictum est ,,masculum et feminam", nisi in corpore recte intellegimus. Vgl. E. Ann Matter, Christ, God and woman in the thought of St. Augustine, in: Augustine and his Critics. Essays in Honour of Gerald Bonner, ed. Robert Dodaro/George Lawless (London/New York 2000) $164-175$.

${ }^{50}$ Augustinus, Confessiones I, 6, 9, ed. Verheijen 5: Quid ante hac etiam, dulcedo mea, Deus meus? Fuine alicubi aut aliquis? Nam quis mihi dicat ista, non habeo; nec pater nec mater potuerunt nec aliorum experimentum nec memoria mea. Vgl. Lacan, Seminar $1,97-103$.
} 
begreifbar zu machen und sie damit auszulösehen zu verdrängen. ${ }^{51}$ Die Stimme der Geschlechterdifferenz hat sich das Subjekt einverleibt, der *sexus hat sich dem Identitätssprechen, dem Sich-als-Jemand-Aussagen aufgepfropft. ${ }^{52}$ Die Wahrnehmungsidentität wird von der Spaltung zum Ort des Anderen durchzogen, sie markiert und verbannt das Andere als Symbolisches, als Objekt. ${ }^{53}$ Der *sexus wird zum Gradmesser im permanenten Ringen zwischen Sein und Nichts, zwischen Da und Fort. Damit wird er in die Strukturlogik der Schöpfungshierarchie eingeschrieben, er wird zu einer logischen (im Sinn von sprachlichen) Komponente des Menschseins, die ihn vom Einen spaltet. ${ }^{54}$ Die irrueduzible Oppositionierung innerhalb des Humanen - wenn denn der Begriff des Diskurses eine solche Begrenzung, und sei es als sein Spiegelbild, überhaupt zuläßt - dieses Herausnehmen hat Verlust zur Folge: das Ich nimmt sich nur mehr als Aus-Gestelltes, Zerstreutes, Distanziertes wahr, und es existiert nur im Aufkommen eines Wunsches: sich in sich selbst zu versetzen und sich in- und auswendig zu lernen. Es formiert sich über dem Abgrund der Spaltung, hebt von sich zu sprechen an.

Ist das Symbolische erst einmal installiert, legt es den (geschlechtlichen) Körper und das Geschlecht fest, es ordnet dem Subjekt seinen Ort in der Genealogie zu, es bestimmt weitgehend seine Lebenswirklichkeit, die für Lacan durch die Signifikanten determiniert wird. Das gilt auch für die geschlechtliche Identität, für die ja weniger, wie etwa Freud annahm, die Anatomie das Schicksal ist, sondern die weitgehend durch den Diskurs des Anderen, durch das Symbolische bestimmt wird. Das gilt aber nicht nur für den geschlechtlichen Körper, sondern für den Körper im allgemeinen, der beispielsweise in der conversio, unter dem Impuls des Signifikanten, zu einem anderen, nunmehr beschriebenen Körper wird. Das Symbolische, das Sprachliche legt sich nicht nur wie ein Schleier über Vorhandenes, sondern das Vorgegebene, in diesem Falle der Körper, wird in seine Ordnung gezwungen, von ihm konvertiert und subvertiert. Dies bedeutet den Primat des Signifikanten.

Die von Augustinus konstatierten intellektuellen und physischen Differenzen zwischen Frau und Mann, die sexuellen Markierungen, werden nicht nur mit ihren unterschiedlich bewerteten Aufgabenbereichen - die Frau ist die Gehilfin des Mannes - und der materiellen Abhängigkeit der Frau begründet. Die Differenzen sind darüberhinaus ein Symbol für die Funktionsweise des menschlichen Verstandes. Die Theologie der Verinnerlichung, die den nach dem Ewigen strebenden homo interior vom auf das Zeitliche orientierten homo exterior abhebt, wird zum Spiegelbild einer Ordnung der Dinge. Diese v.a. in De trinitate entwickelte Systematisierung menschlicher Befindlichkeiten erhält ihre Tiefenstruktur durch folgende Begründung: Der homo interior sollte unablässig nach den ewigen Dingen streben. Das würde aber seine Überlebenschancen empfindlich einschränken. Daher kommt es zu einer Abspaltung, einer Fraktur und Entfremdung. Anders formuliert: der soziale Raum, in dem sich der Mensch aufhält, wird als einer verstanden, der nur mit Kompromissen und durch die Kontrolle des individuellen Ego bewohnbar ist. Folgenschwer ist in dieser Anthropologie allerdings die Verbindung von Weiblichkeit, Zeitlichkeit und homo exterior. Die prinzipielle geistige Gleichwertigkeit der Frau hat dabei auf ihre körperliche Existenz kaum Einfluß. Sie bleibt innerhalb der anthropologischen Ordnung auf bestimmte Rollenbilder beschränkt - die Gehilfin, die Ehefrau, v.a. die Gebärerin. ${ }^{55}$

Damit ist zunächst die gesellschaftliche Funktion der Frau charakterisiert. ${ }^{56}$ Die Geschlechterdifferenz wird darüber hinaus zum Symbol für die Aufgabenteilung im Verstand. Steht der Mann für intellectus, sapientia,

\footnotetext{
${ }^{51}$ Vgl. Theodor W. Adorno, Negative Dialektik (Gesammelte Schriften 6, Frankfurt am Main ${ }^{5} 1996$ ) bes. 163-171; 184-192; Jacques Derrida, Randgänge der Philosophie (Wien $\left.{ }^{2} 1999\right)$ 31-40.

${ }_{52}$ Vgl. Jacques Derrida, Auslassungspunkte (Wien 1998) 292-295.

${ }^{53}$ Lacan, Seminar 1, 104-107; Jacques Derrida, Die Schrift und die Differenz (Frankfurt am Main 1976).

${ }^{54}$ Augustinus, De civitate Dei libri viginti duo XIII, 13 (ed. Bernhard Dombart/Alphons Kalb, CC SL 47, 14, 2, Turnhout 1955) 395; ders., De libero arbitrio libri tres II, 19, 52-20, 54 (ed. Wilhelm M. Green, CC SL 29, 2, 2, Turnhout 1970) 205-321, hier 272f.

${ }_{55}$ Augustinus, De ordine libri duo I, 11, 31 (ed. Wilhelm M. Green, CC SL 29, 2, 2, Turnhout 1970) 87-137, hier 105; vgl. Feminist Interpretations of Saint Augustine, ed. Judith Chelius Stark (Pennsylvania 2007); Würde und Rolle der Frau in der Spätantike, ed. Cornelius Petrus Mayer (Beiträge des 2. Würzburger Augustinus-Studientages am 3. Juli 2004, Würzburg 2007); Müller, Artikel „femina“; William M. Alexander, Sex and philosophy in Augustine, in: Augustinian Studies 5 (1974) 197-208, hier 201ff.; Kari Elisabeth Børresen, Gender and exegesis in the Latin Fathers, in: Augustinianum 40 (2000) 65-76; George Lawless, "infirmior sexus ... fortior affectus". Augustine's Jo.ev.tr. 121, 1-3: Mary Magdalene, in: Augustinian Studies 24 (2003) 107-118; Magdalena Bussmann, Die Frau - Gehilfin des Mannes oder eine Zufallserscheinung der Natur? Was die Theologen Augustinus und Thomas von Aquin über Frauen gedacht haben, in: Auf der Suche nach der Frau im Mittelalter. Fragen, Quellen, Antworten, ed. Bea Lundt (München 1991) 117-133.

${ }^{56} \mathrm{Zu}$ dieser Fragestellung vgl. grundlegend: Kari Elisabeth Børresen, Subordination and Equivalence: The Nature and Role of Woman in Augustine and Thomas Aquinas (Washington D.C. 1981); dies., Patristic "feminism": the case of Augustine, in: Augustinian
} 
ratio, so symbolisiert die Frau die anima, die zwischen Körper und Geist vermittelt, oder das Fleisch. ${ }^{57}$ Die Frau wird damit zum prinzipiell Anderen.

„Wir sehen, ... wie in der menschlichen Seele etwas ist, das durch Urteil und Überlegung herrscht, ein anderes, das sich unterwirft, um zu gehorchen, so sehen wir auch in der sinnlichen Welt die Frau dem Mann unterworfen, die zwar bezüglich des Geistes dieselbe Beschaffenheit der vernünftigen Erkenntnis besäße, aber durch das weibliche Geschlecht dem männlichen Geschlecht in derselben Weise unterworfen sein sollte, wie der Trieb zum Handeln sich unterwirft, um von der Vernunft des Geistes die Erkenntnis des richtigen Handelns zu empfangen." ${ }^{\text {"58 }}$

Dies ist allerdings nur vor einer Differenzierung in der augustinischen Symbolsprache zu sehen: WeiblichSein und Männlich-Sein müssen von Frau und Mann abgelöst werden. Der Symbolcharakter des Weiblichen zeigt, daß es sich dabei nicht nur um eine bloße Geschlechtscharakteristik handelt. Weiblichkeit steht für eine bestimmte geistige Disposition. In De vera religione schreibt Augustinus beispielsweise: „Haben doch auch (christliche) Frauen etwas Männliches an sich, womit sie die weiblichen Lüste unterjochen, Christus dienen und die Begierde beherrschen. ${ }^{\text {" }} 9$

Die Konzentration auf die Innerlichkeit birgt für die Frau wesentlich größere Probleme, steht sie doch ihrer primären sozialen Bestimmung entgegen. Die größtmögliche Annäherung an das männliche Niveau, die eine Frau erzielen kann, erreicht die gottgeweihte Jungfrau. ${ }^{60}$ Die asketische Frau geht damit nicht nur an die Grenzen menschlicher Erkenntnis, sondern auch an die zwischen Mann und Frau. Unschwer läßt sich darin ein hohes Potential an Sozialdisziplinierung erkennen. Die Frau ist, wie in De opere monachorum ausgeführt wird, weder so vernünftig noch so selbstbeherrscht wie der Mann, und bedarf daher ständiger Kontrolle. ${ }^{61}$ Nur

Studies 25 (1994) 139-152; Tarsicius J. van Bavel, Augustine's view on women, in: Augustiniana 39 (1989) 5-53; Elizabeth Clark, St. Augustine on Marriage and Sexuality (Selections from the Fathers of the Church 1, Washington D.C. 1996); Peter Brown, Augustine and Sexuality (Berkeley 1983); ders., The Body and Society; Margaret R. Miles, Desire and Delight. A New Reading of Augustine's Confessions (New York 1992); Kim Power, Veiled Desire: Augustine's Writings on Women (London 1995); Women of Spirit: Female Leadership in the Jewish and Christian Traditions, ed. Rosemary R. Ruether/Eleanor McLaughlin (New York 1979); John C. Bauerschmidt, Sexual Difference and the Relation of the Sexes in the Theology of Saint Augustine (Oxford 1994); Rosemary R. Ruether, Sexism and God-Talk (London 1983); Silvia Soennecken, Misogynie oder Philogynie? Philologisch-theologische Untersuchungen zum Wortfeld Frau bei Augustinus (Kontexte. Neue Beiträge zur Historischen und Systematischen Theologie 13, Frankfurt am Main 1993); Roger Kiska, Augustine: Sex, Desire and Marriage (Diss. Vanderbilt 1999); David G. Hunter, Augustine, Sermon 354A*: Its place in his thought on marriage and sexuality, in: Augustinian Studies 33 (2002) 39-60; F. Ellen Weaver/Jean Laporte, Augustine and women: relationships and teachings, in: Augustinian Studies 12 (1981) 115-131; John J. Hugo, St. Augustine on Nature, Sex and Marriage (Chicago 1969).

${ }^{57}$ Augustinus, De genesi ad litteram II, 12, ed. Zycha 88-90; vgl. Daniela Lachs, Die Ausgrenzung des Weiblichen in der christlichen Philosophie am Beispiel der Trinitätsproblematik bei Augustinus (Dipl.arbeit Wien 1994) bes. 39-41., 114-120.

${ }_{58}$ Augustinus, Confessiones XIII, 32, 47, ed. Verheijen 270: ... videmus umidam usquequaque naturam piscibus et beluis et altibus fecundatam, quod aeris corpulentia, quae volatus avium portat, aquarum exhalatione concrescit. Videmus terrenis animalibus faciem terrae decorari, hominemque ad imaginem et similitudinem tuam, cunctis inrationabilibus animantibus ipsa tua imagine ac similitudine, hoc est rationis et intellegentiae virtute, praeponi; et quemadmodum in eius anima aliud est, quod consulendo dominatur, aliud, quod subditur ut obtemperet, sic viro factam esse etiam corporaliter feminam, quae haberet quidem in mente rationabilis intellegentiae parem naturam, sexu tamen corporis ita masculino sexui subiceretur, quemadmodum subicitur appetitus actiones ad concipiendam de ratione mentis recte agendi sollertiam videmus haec et singula bona et omnia bona valde.

59 Augustinus, De vera religione liber unus 41, 78 (ed. Klaus-Detlev Daur, CC SL 32, 4, 1, Turnhout 1962) 169-260, hier 238f.: Hoc et feminis praecipi potest non maritali, sed fraterno iure, quo iure in Christo nec masculus nec femina sumus. Habent enim et illae virile quiddam, unde femineas subiugent voluptates, unde Christo serviant et imperent cupiditati.

${ }^{60}$ Augustinus, De sancta virginitate liber unus (ed. Joseph Zycha, CSEL 41, 5/3, Prag/Wien/Leipzig 1900) 233-302; ders., De bono coniugali liber unus 12, 14; 14, 16; 23, 30 (ed. Joseph Zycha, CSEL 41, 5, 3, Prag/Wien/Leipzig 1900) 185-231, hier 205f., 208f., 225. Vgl. Rosemary R. Ruether, Misogynism and virginal feminism in the fathers of the church, in: Religion and Sexism. Images of Women in the Jewish and Christian Traditions, ed. Rosemary R. Ruether (New York 1974) 150-183; Peter Brown, The notion of virginity in the early church, in: Christian Spirituality: Origins of the Twelfth Century, ed. Bernard McGinn/John Meyendorf (New York 1985) 427-443; Kate Cooper, The Virgin and the Bride. Idealized Womanhood in the Late Antiquity (Cambridge-Mass./London 1996); David G. Hunter, Augustinian pessimism? A new look at Augustine's teaching on sex, marriage and celibacy, in: Augustinian Studies 25 (1994) 153-177; ders., Augustine and the making of marriage in Roman North Africa, in: Journal of Early Christian Studies 11, 1 (2003) 63-85; Philip Lyndon Reynolds, Marriage in the Western Church. The Christianization of Marriage during the Patristic and Early Medieval Periods (Supplements to Vigiliae Christianae 24, Leiden 1994) 241-311; Aimé Solignac, La femme, la sexualité et le mariage dans le De Genesi, in: Bibliothèque augustinienne. Oeuvres de saint Augustin 49 (1972) 516-530.

${ }^{61}$ Augustinus, De opere monachorum liber unus 32, 40 (ed. Joseph Zycha, CSEL 41, 5, 3, Prag/Wien/Leipzig 1900) 529-596, hier $591-594$ 
wenn sie sich in die hierarchische Ordnung der Dinge einfügt, kann sie ihren Rollenbildern entsprechen. Auch die gesellschaftsutopische Idee der Auferstehung bleibt einer sozialen Ordnung verpflichtet: Augustinus verwehrt sich explizit gegen die Annahme, daß die Frauen nach der Auferstehung in Männer verwandelt werden würden. In De civitate Dei schreibt er:

„Das weibliche Geschlecht ist ja kein Gebrechen, sondern Natur. Begattung freilich und Geburt wird es dann nicht mehr geben. Die weiblichen Glieder werden dann nicht mehr dem alten Zweck angepaßt sein, sondern der neuen Zier, und nicht mehr die Begehrlichkeit des Betrachters reizen, die ja nicht mehr existiert. "62

Und dennoch ist nur vor dem Hintergrund einer Auflösung der Differenzen die Wiedererlangung der Identität des animus denkbar.

„Obwohl das, was man sich innerlich nur unter dem einen Verstand des Menschen vorstellt, äußerlich bei zwei Menschen verschiedenen Geschlechts leiblich gebildet ist, wird trotzdem auch die Frau, weil sie dem Leib nach weiblich ist, erneuert im Geist ihres Verstandes in der Kenntnis Gottes nach dem Bild dessen, der sie erschaffen hat, denn in diesem Bild existiert kein Männlich oder Weiblich.“63

Ähnlich liest man in De trinitate: „Denn weil die Frauen dort nach dem Bild Gottes erneuert werden, wo es kein Geschlecht gibt, so ist dort der Mensch nach dem Bild Gottes geschaffen, wo es kein Geschlecht gibt, das heißt im Sinne des Geistes.“,64 und in den Confessiones: „Denn du schufest den Menschen als Mann und Frau in derselben Weise in deiner geistlichen Gnade, wo nach dem leiblichen Geschlecht weder Mann noch Frau, Jude noch Grieche, Knecht noch Freier sind.“"65

\section{PROIECTIO}

Augustinus ist hier nicht allein geblieben. Weiblichkeit ist ein manifest gewordenes Symbol für die Bedrohung, ein bis ins Obsessive gesteigertes Dispositiv: der Frauenkörper bleibt aufs engste mit Begehrlichkeit verbunden, er wird hysterisiert, mit Technologien der Macht überschüttet. ${ }^{66}$ Er wird in der christlichen Morallehre keineswegs geleugnet oder wegretouchiert - es wird auf ihn zugegriffen, er wird mit Differenzierungen überhäuft, er wird in soziale Ordnungen gepreßt, er wird einer Ökonomie der Erlösung einverleibt. Die Frau wird verschleiert, um sie sichtbar zu machen und in ihrer Differenz aufzudecken.

„Weil sie [die Frau] aber durch ihr körperliches Geschlecht vom Mann verschieden ist, konnte ordnungsgemäß durch ihre körperliche Verschleierung jener Teil des Verstandes versinnbildlicht werden, der zur Leitung des Zeitlichen abgleitet, sodaß das Bild Gottes nur in jenem Teil des Geistes bleibt, in dem er der Anschauung und Erwägung der ewigen Vernunft anhängt, über den offensichtlich nicht nur die Männer, sondern auch die Frauen verfügen.““67

\footnotetext{
${ }^{62}$ Augustinus, De civitate Dei XXII, 17, ed. Dombart/Kalb 835: Non est autem vitium sexus femineus, sed natura, quae tunc quidem et a concubitu et a partu inmunis erit; erunt tamen membra feminea non adcommodata usui veteri, sed decori novo, quo non adliciatur adspicientis concupiscentia, quae nulla erit, sed Dei laudetur sapientia atque clementia, qui et quod non erat fecit et liberavit a corruptione quod fecit. Vgl. Seelbach, Das weibliche Geschlecht.

${ }^{63}$ Augustinus, De genesi ad litteram III, 22, ed. Zycha 89: Itaque quamvis hoc in duobus hominibus diversi sexus exterius secundum corpus figuratum sit, quod etiam in una hominis interius mente intellegitur, tamen et femina, quia corpore femina est, renovatur etiam ipsa in spiritu mentis suae in agnitionem Dei secundum imaginem eius, qui creavit, ubi non est masculus et femina. Vgl. Gal $3,28$.

${ }^{64}$ Augustinus, De trinitate XII, 7, 12, ed. Mountain 367: Sed quia ibi renovantur ad imaginem Dei ubi sexus nullus est, ibi factus est homo ad imaginem Dei ubi sexus nullus est, hoc est in spiritu mentis suae. Vgl. David Vincent Meconi, Grata sacris angelis: Gender and the Imago Dei in Augustine's De Trinitate XII, in: American Catholic Philosophical Quarterly 74 (2000) 47-62; Katherin A. Rogers, Equal before God: Augustine on the nature and role of women, in: Nova Doctrina Vetusque. Essays on Early Christianity in Honor of Frederic W. Schlatter, ed. Douglas Kries/Catherine Brown Tkacz (American University Studies, Series 7, Theology and Religion 207, New York 1999) 169-185.

${ }_{65}$ Augustinus, Confessiones XIII, 23, 33, ed. Verheijen 261: ... masculum enim et feminam fecisti hominem hoc modo in gratia tua spiritali, ubi secundum sexum corporis non est masculus et femina, quia Iudaeus neque Graecus neque servus neque liber ...

${ }^{66}$ Siehe dazu: Michel Foucault, Der Wille zum Wissen. Sexualität und Wahrheit 1 (Frankfurt am Main 1983).

${ }^{67}$ Augustinus, De trinitate XII, 7, 12, ed. Mountain 367: ... sed quia sexu corporis distat a viro, rite potuit in eius corporali velamento figurari pars illa rationis, quae ad temporalia gubernanda deflectitur, ut non maneat imago Dei nisi ex qua parte mens hominis aeternis rationibus conspicuendis vel consulendis adhaerescit, quam non solum masculos sed etiam feminas habere manifestum est. Vgl. Augustinus, Soliloquiorum libri duo I, 12, 21 (ed. Wolfgang Hörmann, CSEL 89, 1, 4, Wien 1986) 1-98, hier $32 f$.
} 
Es sei daran erinnert, daß die Verschleierung der Frau das sichtbare Symbol ihres Status als Eigentum ihres Ehemannes war, das sich in der christlichen Welt in ein Symbol der Unterordnung verwandelte.

Der augustinische Wunsch nach Auflösung der Geschlechterdifferenz in eine androgyne Universalität legt dabei Verdunkelungen offen - es sei an Augustinus' manichäische Phase erinnert, in der Licht und Finsternis sein Denken formten. In diesem dualistischen Denken kann das Chaos nur vom Licht der Erkenntnis überwunden werden. Als einem Hörer der Lehre Manis waren dem jungen Augustinus Sexualität und Gesellschaft zu Antithesen geworden. Die Form der „wahren Gesellschaft“ bestünde aus einer lichterfüllten, von der Materie befreiten Harmonie. Sexualität und Fortpflanzung bedeutete daher eine Zusammenarbeit mit dem Reich der Finsternis. Allein in der Asexualität des animus, in einer Art drittem Geschlecht jenseits binärer Codes ist eine Gleichberechtigung von Frau und Mann denkbar. Der *sexus wird daher zum Gradmesser auf dem Weg einer retrospektiven Suche nach einem nicht-zersplitterten Ich - einer transzendenten Figur jenseits der zeitlichen Flexionen, oder einem narzißtischen Ich in der Form der leeren Zeit, ohne zeitliche Inhalte und ohne semantische Differenz. ${ }^{68}$ Das (Saussure'sche) Zeichen hat eine unauflösbare Zwitternatur, das augustinische eine Sehnsucht nach Unauflösbarkeit. ${ }^{69}$

„Gedenken will ich meiner Befleckungen und des Verderbens meiner Seele im Fleisch, nicht weil ich sie liebe, sondern daß ich dich liebe, mein Gott. Liebe zu deiner Liebe ist es, die mich noch einmal die schändlichen Wege durchwandern läßt im Geiste mit der Bitterkeit der neu auflebenden Erinnerung, auf daß du mir süß werdest, o Süßigkeit, die nicht trügt, o Wonne, die zu Glück und Frieden führt, und wenn ich mich sammle von der Zerstreuung, von der ich stückweise zerrissen wurde, da ich von dir, dem Einen, abgewandt, mich in die Vielheit verlor.“70

In all dem liegt eine revolutionäre Forderung nach der Auflösung eines fiktiven, niemals greifbaren, aber dennoch so wirksamen Gesetzes, das die Trennlinien der den Körpern eingravierten Differenzen regelementiert, einer Kontrollgrammatik, durch die das symbolon der kohärenten Ordnung aufgefaltet, differenziert, bereitgestellt wurde: als ein Aufschub, ein Umweg, ein Diastema, ein unvermeidlicher semantischer Horizont, der erlöschen soll - ein symbolon allerdings, das niemals ein Ganzes war. ${ }^{71}$

Damit sind wir wieder bei der Ausgangsfrage nach dem Begehren angelangt. Augustinus' Confessiones - ein textuelles Ich auf der Suche nach einer ursprünglichen Ordnung (recolens vias meas), die aus Selbstverschuldung zerstört wurde, wobei dieser Verlust in der Schöpfungsordnung ursächlich mit dem Begehren verbunden ist. Unübersehbar ist dabei das Element der Bestrafung, das man auch als Subversion des Begehrens beschreiben könnte. Damit aber erhält die Funktion des Begehrens eine weitere Dimension: sie ist nicht nur den Zufällen der Geschichte des Subjekts ausgesetzt, sondern unterliegt strukturellen Elementen, einer fundamentalen Ordnung, die etwas grundsätzlich Bedrohliches weil Abgespaltenes verrät. ${ }^{72}$

\footnotetext{
${ }^{68}$ Vgl. dazu Augustinus, Confessiones XI, 14, 17-31, 41, ed. Verheijen 202-216; Derrida, Auslassungspunkte 167-173; Judith Butler, Gender Trouble. Feminism and the Subversion of Identity (New York 1990); Knut Reinartz, Sexualität und christliches Menschenbild. Augustins Bewertung der Geschlechtlichkeit in der Beschreibung seines Lebens in den „Confessiones“(Marburg 2007) bes. 70-77.

${ }^{69}$ Ferdinand de Saussure, Cours de linguistique générale (Paris 1916); [dt. Übers.: Grundfragen der allgemeinen Sprachwissenschaft (Berlin $\left.\left.{ }^{2} 1967\right)\right]$ 83-93.

70 Augustinus, Confessiones II, 1, 1, ed. Verheijen 18: Recordari volo transactas foeditates meas, et carnales corruptiones animae meae, non quod eas amem, sed ut amem te, Deus meus. Amore amoris tui facio istuc, recolens vias meas nequissimas in amaritudine recogitationis meae, ut tu dulcescas mihi, dulcedo non fallax, dulcedo felix et secura, et colligens me a dispersione, in qua frustatim discissus sum, dum ab uno te aversus in multa evanui. Vgl. Remo Bodei, Ordo Amoris. Augustinus, irdische Konflikte und himmlische Glückseligkeit (Wien 1993) 119-123; Wolfgang C. Schneider, Das Ende der antiken Leiblichkeit. Begehren und Enthaltsamkeit bei Ambrosius, Augustin und Maximian, in: Frauenwelten in der Antike. Geschlechterordnung und weibliche Lebenspraxis, ed. Thomas Späth/Beate Wagner-Hasel (Stuttgart/Weimar 2000) 412-426; Jörn Müller, Zerrissener Wille, Willensschwäche und menschliche Freiheit bei Augustinus. Eine analytisch motivierte Kontextualisierung von Confessiones VIII, in: Philosophisches Jahrbuch 114 (2007) 49-72; Christoph Horn, Willensschwäche und zerrissener Wille. Augustinus' Handlungstheorie in Confessiones VIII, in: Unruhig ist unser Herz. Interpretationen zu Augustins Confessiones, ed. Michael Fiedrowicz (Trier 2004) $105-122$.

${ }^{71}$ Vgl. Derrida, Auslassungspunkte $177 \mathrm{f}$.

72 Augustinus, Confessiones X, 31, 43-47, ed. Verheijen 177-180; ders., De nuptiis et concupiscentia ad Valerium libri duo I, 8, 10-17, 19; I, 21, 23; I, 13, 25 (ed. Karl Urba/Joseph Zycha, CSEL 42, 8, 2, Prag/Wien/Leipzig 1902) 207-319, hier 221-232, 236-238; vgl. Slavoj Žižek, Das Unbehagen im Subjekt (Wien 1998).
} 
„Ich glaubte ja immer noch, nicht wir seien es, die sündigen, sondern es sündige in uns eine andere, nicht näher bekannte Natur (nescio quam aliam in nobis peccare naturam), und meinem Hochmut schmeichelte der Gedanke, außer Schuld zu sein und, wenn ich etwas Böses getan hatte, nicht bekennen zu müssen, daß ich es getan, bekennen, auf daß Du meine Seele heilen würdest, weil sie an dir auch gesündigt hat. Ich war gewohnt, mich freizusprechen und etwas unbekanntes anderes schuldig zu sprechen, das in mir stecke und gar nicht ich sei. Tatsächlich aber stand hinter dem Ganzen ich allein, und nur meine Gottferne war es, die mich wider mich aufgespaltet hatte, und das war Sünde, um so heilbarer, als ich selbst ja nun vermeinte, nicht Sünder zu sein , und es war eine verdammenswerte Ungerechtigkeit, daß ich - zu meinem Verderben - lieber Dich, allmächtiger Gott, in mir überwunden sah, als mich - zu meinem Heil - überwunden von Dir.“"73

Die alia natura, das Unbekannte, das in einem handelt, produziert ein häretisches Gegenbild, ein WiderIch. Die Gefahr liegt daher in der Unwissenheit, die der Mensch in bezug auf sein Begehren hat, wobei sich dies weniger auf die Unwissenheit bezieht, was er beansprucht, als vielmehr auf das Nichtwissen des Ortes, von wo aus er begehrt. ${ }^{74}$ Das Begehren offenbart sich deshalb in einer Entfremdung. ${ }^{75}$

„Doch siehe, allmählich empfand ich, wo ich war, und wollte meine Wünsche denen kundtun, die sie erfüllen sollten; doch nicht vermochte ich es, weil jene in meinem Innern wohnten, diese aber außer mir, und mit keinem ihrer Sinne vermochten sie es, in die Tiefe meiner Seele zu dringen. Daher strampelte und schrie ich in einer meinen Wünschen, deren nur wenige waren und nur solche, die meiner Fähigkeit entsprachen, nicht ganz gleichenden Weise. Denn ganz entsprechend waren sie nicht. Und ward mir nicht gewillfahrt, weil man entweder meine Wünsche nicht verstehen konnte oder ihre Erfüllung spärlich war, so ward ich zornig auf die Großen, die mir nicht untertan, und die Freien, die mir nicht zu Diensten waren, und suchte mich an ihnen durch Geschrei zu rächen." ${ }^{\text {"76 }}$

Ursächlich stößt daher das Individuum bei seiner Suche nach sich selbst auf das Außen, das Fremde, das Andere, das Differente, in dem die Ich-Inszenierung permanent wiederholt wird. Das Universum des Subjekts wirkt entfremdend, indem es das Subjekt vom Anderen abschließt und als ein schützendes Imaginäres etabliert wird. Gleichzeitig empfängt es den symbolischen Wert der Entfremdung, der im Anderen verborgen liegt - der peregrinus im saeculum, wie er in unzähligen augustinischen Texten begegnet, die Möglichkeit der alienatio von den Grenzen des Ego. ${ }^{77}$

Ein Spiel der Differenzen begleitet das ego, bei dem der *sexus (als Erkenntnis) gezwungen ist, die IchPerzeptionen in sich selbst zu spalten und zur Erkundung über sich selbst durch die anderen bzw. der anderen durch sich selbst anzuhalten. Dieses Spiel kulminiert in der Vision, in der die Sehnsucht nach Vereinigung mit dem Außen in sich selbst zum Ausdruck gebracht wird. Der *sexus entzieht sich dabei aber unzufrieden (und) ununterbrochen. ${ }^{78}$ Der Ort des ego bleibt somit paradox.

„Und so stieg ich stufenweise empor von den Körpern zur Seele, die mittels des Körpers empfindet, von dieser zu ihrer inneren Kraft, der die Sinne des Körpers von einer Außenwelt Kunde bringen - soweit reicht auch das Vermögen der Tiere -, von dort wiederum zu der beurteilenden Kraft [der Vernunft], die die Sinneseindrücke zur Prüfung emp-

\footnotetext{
${ }^{73}$ Augustinus, Confessiones 5, 10, 18: Adhuc mihi videbatur non esse nos, qui peccamus, sed nescio quam aliam in nobis peccare naturam et delectabat superbiam meam extra culpam esse et, cum aliquid mali fecissem, non confiteri me fecisse, ut sanares animam meam, quoniam peccabat tibi, sed excusare me amabam et accusare nescio quid aliud, quod mecum esset et ego non essem. Verum autem totum ego eram et adversus me inpietas mea me diviserat, et id erat peccatum insanabilius, quo me peccatorem non esse arbitrabar, et execrabilis iniquitas, te, deus omnipotens, te in me ad perniciem meam, quam me a te ad salutem malle superari.

${ }^{74}$ Augustinus, Confessiones X, 6, 8-6, 10, ed. Verheijen 158-160; Lacan, Schriften 2, 190.

${ }^{75}$ Lacan, Schriften 2, 189, 191, 251f.

${ }^{76}$ Augustinus, Confessiones I, 6, 8, ed. Verheijen 4: Et ecce paulatim sentiebam, ubi essem, et voluntates meas volebam ostendere eis, per quos implerentur, et non poteram, quia illae intus erant, foris autem illi, nec ullo suo sensu valebant introire in animam meam. Itaque iactabam et membra et voces, signa similia voluntatibus meis, pauca quae poteram, qualia poteram: non enim erant veri similia. Et cum mihi non obtemperabatur, vel non intellecto vel ne obesset, indignabar non subditis maioribus, et liberis non servientibus, et me de illis flendo vindecabam. Tales esse infantes didici, quos discere potui, et me talem fuisse magis mihi ipsi indicaverunt nescientes quam scientes nutritores mei. Vgl. Achim Wurm, Locus non locus. Der Stil der Innerlichkeit in Augustins Confessiones, in: Raum und Raumvorstellungen im Mittelalter, ed. Jan A. Aertsen/Andreas Speer (Miscellanea mediaevalia 25, Berlin/New York 1998) 452-470.

77 Robert A. Markus, Alienatio. Philosophy and eschatology in the development of an Augustinian idea, in: Augustine 1, ed. John Dunn/Ian Harris (Cheltenham 1997) 456-475; Cornelius Petrus Mayer, Alienatio, in: Augustinus-Lexikon 1 (1986-1994) 228-233; Gerhart B. Ladner, Homo Viator: Mediaeval ideas on alienation and order, in: Speculum 42 (1967) 233-259.

${ }^{78}$ Augustinus, De trinitate X, 5, 7; X, 10, 13-16, ed. Mountain 320f., 326-329.
} 
fängt. Diese aber erkannte sich in mir selbst als veränderlich und erhob sich zur Erkenntnis ihrer selbst, entzog sich der bisher gewohnten Denkweise und machte sich frei von dem verworrenen, ihr widersprechenden Schwarm von Trugbildern, um das Licht zu finden, von dem sie erleuchtet würde, da sie ohne allen Zweifel behauptete, daß das Unwandelbare dem Wandelbaren vorzuziehen sei, und um zu erforschen, woher sie das Unwandelbare kenne, welches sie, ohne es irgendwie zu kennen, nimmermehr so sicher dem Wandelbaren vorziehen würde. Und so gelangte meine vernünftige Kraft zu dem wesentlichen Sein im Moment eines zagenden Erblickens. “79

Das Gute und das Ästhetische bilden die einzige Schranke, die das Subjekt vor dem radikalen Begehren, das in der (Selbst-)destruktion mündet, einhalten läßt. ${ }^{80}$

\section{DISIECTUM}

Bei der Interpretation der Zeichen bleibt ein nicht einholbarer Rest, dessen unaufhörliche Wirkung zur imaginären Ausgestaltung des Nichtvorstellbaren, Uneinholbaren führt. Die Zeichen sind unerschöpflich. Das Imaginäre ist die Beziehung des Subjekts zu seinen strukturierenden Identifikationen. Erstreckt sich das Imaginäre über die Zeit und nimmt es die Dimensionen des Zeitlichen an, wird es dis-kursiv. Es durchläuft die Szenographie einer personalen Idealisierung in Form eines funktionalen Ich-Bildes. In diesem Bild sind sowohl die Funktion der Suche (nach dem Überleben) als auch der Konflikt grundsätzlich angelegt.

„O Herr, zu dir hätte ich die Seele erheben sollen, dir hätte ich aufbürden sollen mein Leid; aber ich wollte es nicht noch vermochte ich es, um so weniger, als ich dich nicht mir als fest und unwandelbar dachte, denn nicht du, sondern ein leeres Trugbild, ein Irrtum war mein Gott. Wenn ich es nun versuchte, hier meine Seele zur Ruhe zu betten, da zerrann es ins Leere und wiederum stürzte es sich auf mich, und ich war mir zuletzt selber ein unglückseliger Ort, an dem ich weder bleiben noch den ich verlassen konnte." ${ }^{\text {(81 }}$

Infelix locus ist, in der Praxis des An-sich-Herantretens, die Erfahrung der Unhaltbarkeit der Annahme eines autonomen Subjektes. Sobald man danach greift, verbirgt es sich hinter einem fragilen System opaker Bilder und bleibt unfaßbar - ein Trugbild, eine profunda et infinita multiplicitas. ${ }^{82}$ Sobald das Selbst in den Fokus des Denkens/Sprechens gerät, entzieht es sich, wird unmitteilbar.

„Das ist die große Macht des Gedächtnisses, übergewaltig, mein Gott, ein geheimes Heiligtum, weit und grenzenlos. Wer kommt zu seinem Grund? Und das ist die Kraft meines Geistes, die meiner Natur angehört; und doch fasse ich selbst nicht ganz, was ich bin. Denn der Geist ist zu eng, um sich selbst zu fassen." ${ }^{\text {(83 }}$

\footnotetext{
79 Augustinus, Confessiones VII, 17, 23, ed. Verheijen 107: Atque ita gradatim a corporibus ad sentientem per corpus animam atque inde ad eius interiorem vim, cui sensus corporis exteriora nuntiaret, et quousque possunt bestiae, atque inde rursus ad ratiocinantem potentiam, ad quam refertur iudicandum, quod sumitur a sensibus corporis; quae se quoque in me comperiens mutabilem erexit se ad intellegentiam suam et abduxit cogitationem a consuetudine, subtrahens se contradicentibus turbis phantasmatum, ut inveniret, quo lumine aspargeretur, cum sine ulla dubitatione clamaret incommutabile praeferendum esse mutabili, unde nosset ipsum inconmutabile - quod nisi aliquo modo nosset, nullo modo illud mutabili certa praeponeret - et pervenit ad id, quod est in ictu trepidantis aspectus.

${ }^{80}$ Augustinus, Soliloquia I, 6, 12-7, 14, ed. Hörmann 19-23; Jacques Lacan, Das Seminar 7. Die Ethik der Psychoanalyse (Berlin 1996) 262, $280 \mathrm{ff}$.

${ }^{81}$ Augustinus, Confessiones IV, 7, 12, ed. Verheijen 46: Ubi autem inde auferebatur anima mea, onerabat me grandis sarcina miseriae, ad te, Domine, levanda erat et curanda, sciebam, sed nec volebam nec valebam, eo magis, quod mihi non eras aliquid solidum et firmum, cum de te cogitabam. Non enim tu eras, sed vanum phantasma et error meus erat Deus meus. Si conabar eam ibi ponere, ut requiesceret, per inane labebatur et iterum ruebat super me; et ego mihi remanseram infelix locus, ubi nec esse possem nec inde recedere.

${ }^{82}$ Augustinus, Confessiones X, 17, 26, ed. Verheijen 168f.; ders. Soliloquia II, 20, 34, ed. Hörmann 93-95; Gilles Deleuze, Differenz und Wiederholung (München ${ }^{2}$ 1997) 94; Lacan, Seminar 1, 305f.; Norbert Fischer, Unsicherheit und Zweideutigkeit der Selbsterkenntnis: Augustins Antwort auf die Frage „quid ipse intus sim“ im zehnten Buch der Confessiones, in: Geschichte und Vorgeschichte der modernen Subjektivität, ed. Reto Luzius Fetz/Roland Hagenbüchle/Peter Schulz (European Cultures 11, Berlin/ New York 1998) 340-366.

${ }^{83}$ Augustinus, Confessiones X, 8, 15, ed. Verheijen 162: Magna ista vis est memoriae, magna nimis, Deus, penetrale amplum et infinitum: quis ad fundum eius pervenit? Et vis est haec animi mei atque ad meam naturam pertinet, nec ego ipse capio totum, quod sum. Ergo animus ad habendum se ipsum angustus est: ut ubi sit quod sui non capit? Numquid extra ipsum ac non in ipso? Quomodo ergo non capit? Multa mihi super hoc oboritur admiratio, stupor adprehendit me. Vgl. Alan Baddeley, The psychology of remembering and forgetting, in: Memory. History, Culture and the Mind, ed. Thomas Butler (Blackwell 1989) 33-60.
} 
Das Phänomen von Anwesenheit und Abwesenheit wird in der Auffindung von Sprache auf eine symbolische Ebene gehoben ${ }^{84}$ In eben diesem Augenblick verdeutlicht sich das Begehren und verpflanzt sich in den Sprechenden, der sich als Sub-jekt zu erfahren lernt: als Subjekt im Verhältnis zum Diskurs und als imaginäres Ich, das als Subjekt verstanden werden soll. Die synchronistische Struktur der Sprache bietet eine Imagination der objektiv erfahrenen Umwelt als Wahrnehmungstableau an und formiert so dieses [Subjekt als Subjekt] in der Form des Subjekts des Begehrens.

„Du hast dem Menschen die Fähigkeit verliehen, von anderen auf sich zu schließen und in betreff der eigenen Person auch dem Zeugnis der Frauen fest zu vertrauen. Denn schon damals war und lebte ich, und schon an der Grenze meiner Kindheit suchte ich Zeichen, um anderen meine Empfindungen deutlich zu machen. Woher aber kommt ein solch beseeltes Wesen, wenn nicht von dir, o Herr?"85

Dieses Verhältnis von Subjekt und Diskurs ist aber keineswegs substantiell und kontinuierlich im Sinn einer Ontologie der Verhältnismäßigkeit, in die sich das Subjekt nur einzubetten bräuchte. Es ist von seiner Struktur her labil und grundsätzlich immer nur über den Anderen als ein Zeichen der Differenz erkundbar. ${ }^{86} \mathrm{ES}$ zeigt sich am deutlichsten beim Anderen. Beim Nicht-Integrierbaren, beim - im Adornoschen Sinn - Nicht-Identischen, Differenten. ${ }^{87}$ Welches jenes Dritte ist, das nicht in die konzeptionelle Kompetenz eines Sprechenden/Schreibenden fällt. Differenz ist dabei vom Nicht-Identischen unterschieden als der Überhang an Ungegenwärtigem, Uninterpretierbarem, Anderem, der sich jedem semiotischen Symbolsystem anhängt wie der Schatten dem Objekt. Die symbolische Dimension der Wirklichkeit ist im Semiotischen geborgen. Der sich ihm entziehende, unvorstellbare, unerfaßbare Rest - das Unvollständige - ist nach Lacan das Reale - ein Übertritt, ein Austritt, ein exodus aus der allgegenwärtigen Konstruktion des Ego als Ego. Es ist das, was seine Wirkung zu entfalten nicht aufhört. Die radikale Differenz zwischen dem Sein und dem Nichts ist daher auf individueller Ebene die Differenz zwischen dem Symbol und dem Realen, zwischen dem Imaginativen und dem Unvollständigen.

„Dieses Alter also [die Kindheit], o Herr, von dessen Durchleben ich keine Ahnung habe, das ich nur nach anderer Glaubwürdigkeit und andern Kindern gefolgert habe, mag ich, obgleich diese Schlüsse vollen Glauben verdienen, kaum zu dem Leben rechnen, das ich in dieser Zeitlich-Weltlichkeit lebe. Denn der dunkle Schleier der Vergessenheit ruht darüber, gerade wie über jenem Leben, das ich im Mutterleib verbracht habe. ${ }^{\text {“88 }}$

Zeit ist der Faktor der Entfremdung, da die spätantike Wahrnehmung der permanenten Immanenz des Göttlichen im Jetzt in der Umwelt auf ein Jenseits disloziert wird, eine Verschiebung von Zeitlichkeit, die den Einzelnen zum Fremden in der Welt, zum Dislozierten, zum peregrinus macht. Der Gedanke der Deplazierung ist in den Confessiones XI formuliert, in denen das Jetzt als unfaßbarer Moment definiert wird, der paradoxerweise nur in Zerdehnung (distentio) zu denken ist, der sich zwischen noch nicht faßbarer Zukunft und nicht mehr faßbarer Vergangenheit aufspannt. Es ist gerade dieses Paradoxon der Zeit, das den Menschen prinzipiell zum Außenstehenden, zum Fremden, zur Umherirrenden und Ortlosen in der Welt macht. Letztlich verdeut-

\footnotetext{
${ }^{84}$ Lacan, Seminar 1, 104ff.

${ }^{85}$ Augustinus, Confessiones I, 6, 10, ed. Verheijen 5: ... et dedisti ea homini ex aliis de se conicere et auctoritatibus etiam muliercularum multa de se credere. Eram enim et vivebam etiam tunc, et signa, quibus sensa mea nota aliis facerem, iam in fine infantiae quaerebam. Unde hoc tale animal nisi abs te, Domine. Vgl. Felix Baffour Asade Asiedu, Following the example of a woman: Augustine's conversions to christianity in 386, in: Vigiliae Christianae 57 (2003) 276-306.

${ }^{86}$ Lacan, Seminar 2, 125; Deleuze, Differenz und Wiederholung 86f.; Michel Foucault, Der Gebrauch der Lüste. Sexualität und Wahrheit 2 (Frankfurt am Main $\left.{ }^{2} 1991\right)$ 10ff.

${ }^{87}$ Adorno, Negative Dialektik 139-207.

${ }_{88}$ Augustinus, Confessiones I, 7, 12, ed. Verheijen 7: Hanc ergo aetatem, Domine, qua me vixisse non memini, de qua aliis credidi et quam me egisse ex aliis infantibus conieci, quamquam ista multum fida coniectura sit, piget me adnumerare huic vitae meae, quam vivo in hoc saeculo. Quantum enim adtinet ad oblivionis meae tenebras, par illi est, quam vixi in matris utero. Vgl. ebd. I, 6, 9, ed. Verheijen 4f.: Et ecce infantia mea olim mortua est et ego vivo. Tu autem, Domine, qui et semper vivis et nihil moritur in te, quoniam ante primordia saeculorum et ante omne, quod vel ante dici potest, tu es et Deus es Dominusque omnium, quae creasti, et apud te rerum omnium instabilem stant causae, et rerum omnium mutabilium inmutabiles manent origines, et omnium inrationalium et temporalium sempiternae vivunt rationes, dic mihi supplici tuo, Deus, et misericors misero tuo, dic mihi, utrum alicui iam aetati meae mortuae successerit infantia mea. An illa est, quam egi intra viscera matris meae? Nam et de illa mihi nonnihil indicatum est et praegnantes ipse vidi feminas. Quid ante hanc etiam, dulcedo mea, Deus meus? Fuine alicubi aut aliquis? Nam quis mihi dicat ista, non habeo; nec pater nec mater potuerunt, nec aliorum experimentum, nec memoria mea. Ders., De trinitate libri quindecim XIV, 5,7 (ed. William J. Mountain, CC SL 50, 16, 2, Turnhout 1968) 429f.
} 
licht sich darin die Faszination des Modells der Diaspora, das ja die Fragen von Zugehörigkeit und gleichzeitig Ausgestoßenheit und in der Fremde-sein zu kombinieren, verändern und adaptieren erlaubt. ${ }^{89}$

Der Begriff, das Symbol, ist für Augustinus die zeitliche Zerdehnung (distentio) der abwesenden Sache. Die Abwesenheit des Bezeichneten ist somit die Voraussetzung für die Aktualisierung jedes Zeichens, wodurch das Symbol eine dynamische Identität in der Differenz Dasein/Fortsein und, mehr noch, eine Oppositionsstruktur vermittelt. Die zwangsläufig auf Signifikanten bezogene episteme kann sich somit nur in der Differenz erfahren. Sobald sich das Subjekt in dieses Verhältnis einnistet, muß es jene Latenz eingehen, die die Umwelt in sich hineinzieht. ${ }^{90}$ Es erfährt Zeitverlust im Sinne der Negation chronologischer Gewißheit. ${ }^{91}$ „Die Seele merkt aber,

${ }^{89}$ Augustinus, De civitate Dei XVIII, 46, ed. Dombart/Kalb 643-645; De civitate Dei libri viginti duo IV, 34 (ed. Bernhard Dombart/Alphons Kalb, CC SL 47, 14, 1, Turnhout 1955) 127. Vgl. dazu aus der zahlreichen Literatur: Flasch, Was ist Zeit?; Ernst A. Schmidt, Zeit und Geschichte bei Augustin (Sitzungsberichte der Heidelberger Akademie der Wissenschaften, phil.-hist. K1. 3, Heidelberg 1985); Odilo Lechner, Idee und Zeit in der Metaphysik Augustins (Salzburger Studien zur Philosophie 5, München 1964); Gerald J.P. O'Daly, Time as Distentio and St. Augustine's Exegesis of Philippians 3, 12-14, in: Revue des études augustiniennes 23 (1977) 265-271; Ulrich Duchrow, Der sogenannte psychologische Zeitbegriff Augustins im Verhältnis zur physikalischen und geschichtlichen Zeit, in: Zeitschrift für Theologie und Kirche 63 (1966) 267-288; Remo Bodei, Ordo Amoris. Augustinus, irdische Konflikte und himmlische Glückseligkeit (Wien 1993); Friedrich-Wilhelm von Herrmann, Augustinus und die phänomenologische Frage nach der Zeit (Frankfurt am Main 1992); Genevieve Lloyd, Augustine and the "problem" of time, in: The Augustinian Tradition, ed. Gareth B. Matthews (Philosophical Traditions 8, Berkeley/Los Angeles/London 1999) 39-60; Alexius J. Bucher, Der Ursprung der Zeit aus dem Nichts. Zum Zeitbegriff Augustins, in: Recherches augustiniennes 11 (1976) 35-51; Norbert Fischer, Sein und Sinn der Zeitlichkeit im philosophischen Denken Augustins, in: Revue des Études augustiniennes 33 (1987) 205-234; ders., Augustins Philosophie der Endlichkeit. Zur systematischen Entfaltung seines Denkens aus der Geschichte der Chorismos-Problematik (Bonn 1987); ders., Die Zeit, die Zeiten und das Zeitliche in Augustins Confessiones, in: Schöpfung, Zeit und Ewigkeit. Augustinus: Confessiones 11-13, ed. Norbert Fischer/Dieter Hattrup (Paderborn/München/Wien/Zürich 2006) 52-64; Johann Kreuzer, Erinnerung, Zeit und Geschichte: Augustin und die Anfänge der mittelalterlichen Philosophie, in: Perspektiven der Philosophie 25 (1999) 37-62; Cornelius Petrus Mayer, „Die Zeiten alle hast du gewirkt“. Zur Geschichtstheologie Augustins, in: Zeit - Endzeit - Ewigkeit, ed. Wolfgang Böhme/Ferdinand Hahn (Herrenalber Texte 78, Karlsruhe 1987) 70-82; History, Apocalypse, and the Secular Imagination. New Essays on Augustine's City of God. Proceedings of a Colloquium held at Green College, the University of British Columbia, 18-20 September 1997, ed. Mark Vessey (Augustinian Studies 30, 2, Bowling Green 1999); Walter Mesch, Reflektierte Gegenwart. Eine Studie über Zeit und Ewigkeit bei Platon, Aristoteles, Plotin und Augustinus (Philosophische Abhandlungen 86, Frankfurt am Main 2003); Christof Müller, Confessiones 13: ,Der ewige Sabbat ${ }^{\star}$ - die eschatologische Ruhe als Ziel der Schöpfung, in: Schöpfung, Zeit und Ewigkeit. Augustinus: Confessiones 11-13, ed. Norbert Fischer/Dieter Hattrup (Paderborn/München/Wien/Zürich 2006) 155-167; Enno Rudolph, Einheit und Differenz. Anmerkungen zu Augustins Zeitauffassung im XI. Buch der Confessiones, in: Einheit als Grundfrage der Philosophie, ed. Karen Gloy/Enno Rudolph (Darmstadt 1985) 102-119; Manfred Scheuer, ,... denn die Zeit selber hast Du geschaffen“ (Conf. 11,14,17). Schöpfung und Zeit in den Confessiones des Augustinus, in: Unruhig ist unser Herz. Interpretationen zu Augustins Confessiones, ed. Michael Fiedrowicz (Trier 2004) 153-170; Ursula Schulte-Klöcker, Das Verhältnis von Ewigkeit und Zeit als Widerspiegelung der Beziehung zwischen Schöpfer und Schöpfung. Eine textbegleitende Interpretation der Bücher XI-XIII der Confessiones des Augustinus (Hereditas. Studien zur Alten Kirchengeschichte 18, Bonn 2000); Thorsten Streubel, Das Wesen der Zeit. Zeit und Bewußtsein bei Augustinus, Kant und Husserl (Epistemata. Würzburger Wissenschaftliche Schriften. Reihe Philosophie 401, Würzburg 2006); Johann Kreuzer, Gestalten mittelalterlicher Philosophie. Augstinus, Eriugena, Eckhart, Tauler, Nikolaus von Kues (Bonn 2000) 23-54; Stephan Grotz, Ewigkeit und Zeit. Zu Augustins Fragen im XI. Buch der Confessiones, in: Allgemeine Zeitschrift für Philosophie 29 (2004) 117-142; Karsten Junk, Das Zeitverständnis des hl. Augustinus im XI. Buch der Confessiones und Aspekte seiner philosophisch-theologischen Rezeption im 20. Jahrhundert (München 2006); Karen Piepenbrink, Christliche Identität und Assimilation in der Spätantike. Probleme des Christseins in der Reflexion der Zeitgenossen (Studien zur Alten Geschichte 3, Mannheim 2005).

${ }^{90}$ Augustinus, De trinitate X, 5, 7, ed. Mountain 321: Ita cum aliud sit non se nosse, aliud non se cogitare (neque enim multarum doctrinarum peritum ignorare grammaticam dicimus cum eam non cogitat quia de medicinae arte tunc cogitat), cum ergo aliud sit non se nosse, aliud non se cogitare, tanta vis est amoris ut ea quae cum amore diu cogitaverit eisque curae glutino inhaeserit attrahat secum etiam cum ad se cogitandam quodam modo redit. Et quia illa corpora sunt quae foris per sensus carnis adamavit eorumque diuturna quadam familiaritate implicata est, nec secum potest introrsus tamquam in regionem incorporeae naturae ipsa corpora inferre, imagines eorum convoluit et rapit factas in semetipsa de semetipsa. Dat enim eis formandis quiddam substantiae suae; servat autem aliquid quo libere de specie talium imaginum iudicet, et hoc est magis mens, id est rationalis intellegentia quae servatur ut iudicet. Nam illas animae partes quae corporum similitudinibus informantur etiam cum bestiis nos communes habere sentimus. Vgl. Augustinus, De magistro liber unus I, 1-2 (ed. Klaus-Detlev Daur, CC SL 29, 2, 2, Turnhout 1970) 139-203, hier $157-159$

${ }^{11}$ Vgl. Rainer Hirschberg, Die Chronologie des Bewußten und dessen ewige Negation durch das Unbewußte, in: Zeit und Zeitlichkeit, ed. Christian Kupke/Martin Heinze/Stephan V. Pflanz/Kai Vogeley (Beiträge der Gesellschaft für Philosophie und Wissenschaft der Psyche 2, Würzburg 1996-1999) 101-117. 
daß sie über etwas verfügt, nur dann, wenn ihr etwas ins Bewußtsein kommt. “92 Die Folgerung daraus ist, ,„... daß, wenn sich das Subjekt verändert, alles, was im Subjekt ist, sich notwendigerweise mitverändert" ${ }^{\text {" }}{ }^{93}$ Darin liegt auch die Bedeutung von Augustinus’ imagines-Begriff, denn die fragile Latenz ist die Erinnerung. „Und doch bin ich gewiß, so unbegreiflich und unauseinandersetzbar es auch ist, daß ich mich auch selbst der Vergessenheit erinnere, durch welche alles, dessen ich mich erinnere, ausgelöscht wird. “94 Die Differenz, die das Signifikat vom Signifikanten unterscheidet, ermöglicht seine als Identität bestimmbare veritas zu unterbrechen und somit Unterscheidungen zu setzen - als vorläufige. Das Differenz-Denken in seiner Unabschließbarkeit ist daher auf die Entdeckung von Abwesendem, Fernem, Fremdem verwiesen, weshalb das differente ZeichenSpiel ins Unendliche führt. Die Grenze zwischen Endlichkeit und Unendlichkeit, die endgültige Ankunft der Zukunft wird dadurch immer aufgeschoben. Der paradoxe Zustand des Zeichenprozesses, der auf der NichtIdentität des Signifikanten mit dem Signifikat beruht, ruft eine imaginäre Figur ins Spiel, die als begründende Kraft theologisch interpretierbar wird.

Das Sprechen der Zeichen unterliegt, wie aus De magistro hervorgeht, nicht nur einer semantischen Ambiguität, sondern auch einer subjektiven Ambiguität. Das Subjekt hat nicht die absolute Konrolle über die Konstituierung der Zeichen. Ohnmacht, Irrtum und Ambivalenz begleiten die Installation der Zeichen und die Etablierung des Diskurses. Das Subjekt vermag keinen Anspruch auf Ursprünglichkeit seiner selbst und des symbolischen Universums zu erheben. „Über das am Ich Entscheidende, seine Selbständigkeit und Autonomie kann nur geurteilt werden im Verhältnis zu seiner Andersheit, zum Nichtich. ${ }^{\text {“95 }}$ Das Sprechen ist nicht nur die Produktion von Differenz - mit all der projektiven Unsicherheit des selbstreflexiven Bezugs -, sondern auch der Verzicht auf die Unmittelbarkeit, die Gegenwart des Objekts. Man könnte von einer projektiven Unabwägbarkeit sprechen.

Die Relation des [Subjekts als Subjekt] zum Diskurs ist insofern fragil, als permanent die Abwesenheit in der Anwesenheit, und die Anwesenheit in der Abwesenheit des Anderen evoziert wird. Begehren und Begierdeobjekt verschmelzen in einem latent erfahrenen Mangel.

„Ich wunderte mich, daß ich dich schon liebte und nicht ein bloßes Trugbild statt deiner. Doch ereiferte ich mich nicht, zum Genuß meines Gottes zu gelangen, sondern bald ward ich hingerissen zu dir durch deine Schöne, bald hinweg von dir durch meine Last und sank mit Seufzen zurück, und diese Last, es war meine Gewohnheit des Fleisches." ${ }^{\text {"96 }}$

Ego verhält sich fragmentiert in einem Ensemble von Subjektfunktionen bzw. -dysfunktionen, wobei das Subjekt in seinen Verhandlungen selbst zu einem Objekt bzw. zu Objekten gemacht wird. Damit unterliegt es dem Zwang mehr oder minder komplexer, integrativer Organisation aufeinander bezogener Objekte, die als polymorphe Zustände, als Ego States begegnen, die ihrerseits ein Eigenleben entfalten können - colligens me a dispersione, in qua frustratim discissus sum, dum ab uno te aversus in multa evanui. ${ }^{97}$ Die Inszenierung des Subjekts (in der doppelten genetivischen Bedeutung) durch das Da und Fort, dem Lacan den Namen Spulenspiel verlieh, ${ }^{98}$ wird hier auf eine spirituelle Ebene projiziert, um der unendlichen Abdrift der Interpretationen des ego entgegenzuhalten. „Und ich fand mich weit von Dir in der Fremde der Unähnlichkeit ..." ${ }^{\text {" Und }}$ ferner:

\footnotetext{
${ }_{92}$ Augustinus, De inmortalitate animae 4, 6; 6, 10f., ed. Hörmann 107, 110-112: Non autem quidquam se habere animus sentit, nisi quod in cogitationem venerit.

${ }_{93}$ Augustinus, De inmortalitate animae 5, 8, ed. Hörmann 108: Sed ne rationi nostrae adversentur, qua dictum est mutato subiecto omne, quod in subiecto est, necessario mutari, videndum est.

${ }^{94}$ Augustinus, Confessiones X, 16, 25, ed. Verheijen 168: Et tamen quocumque modo, licet sit modus iste incomprehensibilis et inexplicabilis, ipsam oblivionem meminisse me certus sum, qua id quod meminerimus obruitur.

${ }_{95}$ Adorno, Negative Dialektik 222.

${ }_{96}$ Augustinus, Confessiones VII, 17, 23, ed. Verheijen 107: Et mirabar, quod iam te amabam, non pro te phantasma: et non stabam frui Deo meo, sed rapiebar ad te decore tuo, moxque diripiebar abs te pondere meo, et ruebam in ista cum gemitu; et pondus hoc consuetudo carnalis.

${ }^{97}$ Augustinus, Confessiones II, 1, 1, ed. Verheijen 18. Vgl. John G. Watkins/Helen H. Watkins, Ego States. Theory and Therapy 1 (New York 1997).

${ }_{98}$ Lacan, Seminar 1, 220-227.

99 Augustinus, Confessiones VII, 10, 16, ed. Verheijen 103: Et inveni longe me esse a te in regione dissimilitudinis, ...
} 
„Daher empfing der Mensch, den du nach deinem Bild geschaffen hast, nicht die Macht über die Lichter des Himmels noch über den verborgenen Himmel selbst noch über Tag und Nacht, die du vor der Schöpfung des Himmels berufen hast, noch über die Sammlung der Wasser, die das Meer sind; wohl aber wurde ihm die Macht gegeben ... über die ganze Erde ... Er urteilt und billigt; er mißbilligt und verwirft; sowohl in der Feier der Geheimnisse, worin diejenigen eingeweiht worden, die dein Erbarmen aus den vielen Wassern hervorzieht, ... wie auch über die Worte und Reden, die dem Ansehen deiner Schrift unterworfen sind und die gleichsam unter dem Firmament umherfliegen, durch Erklärung, Auslegung, Erörterung, Untersuchung, Segnung und Anrufung deiner aus dem Munde hervorbrechen ... Die Ursache, daß alle diese Worte in solcher Weise gesprochen werden mußten, ist der Abgrund der Welt/Zeit, die Blindheit des Fleisches, die unser Auge für die Erkenntnis des Gedachten verdunkelt, sodaß es der Stimme für das Ohr bedarf ..."100

Die episteme verdeutlicht, daß sich der Mensch nicht als Urheber der Signifikanten und damit seiner eigenen Grundlagen begreifen kann. ${ }^{101}$ Sich am infelix locus aufhaltend, erkennt das Subjekt die grundsätzliche Leere seiner selbst und mutiert zum A-subjekt - zum grenzenlosen abiectum, zum verworfenen Entwurf, dem Disjekt, das die Kehrseite des Subjekts und dessen Fragilität und Mutabilität offenkundig werden läßt. Dieses A-subjekt äußert sich besorgt um sich. Es schreibt sich ins Imaginäre ein. Und es unterzieht sich einer symbolischen diskursiven Ordnung, zu der es sich in einem symptomatischen Verhältnis befindet. ${ }^{102}$ Die Prädestination betrifft das Subjekt nicht zuletzt in seiner sprachlichen Bedingtheit. Das Sprechen als das Sprechen des Subjekts, von dem es ausgeht, zielt auf die symbolische Ebene ab. Gäbe es dieses Sprechen nicht, so existierte kein Konflikt mit dem Spiegelbild und keine Unterschiede in der Wahrnehmung der Um-Welt, sondern bloße Wiederholung.

\footnotetext{
100 Augustinus, Confessiones XIII, 23, 34, ed. Verheijen 262: Ideoque homo, quem fecisti ad imaginem tuam, non accepit potestatem luminarium caeli, neque ipsius occulti caeli, neque diei et noctis, quae ante caeli constitutionem vocasti, neque congregationis aquarum, quod est mare: sed accepit potestatem piscium maris et volatilium caeli et omnium pecorum et omnis terrae et omnium repentium, quae repunt super terram. Iudicat enim et approbat, quod recte, improbat autem, quod perperam invenerit; sive in ea sollemnitate sacramentorum, quibus initiantur quos pervestigat in aquis multis misericordia tua; sive in ea, qua ille piscis exhibetur, quem levatum de profundo terra pia comedit; sive in verborum signis vocibusque subiectis auctoritati libri tui, tamquam sub firmamento volitantibus, interpretando, exponendo, disserendo, disputando, benedicendo atque invocando te, ore erumpentibus atque sonantibus signis, ut respondeat populus: amen. Quibus omnibus vocibus corporaliter enuntiandis causa est abyssus saeculi et caecitas carnis, qua cogitata non possunt videri, ut opus sit instrepere in auribus. Ita, quamvis multiplicentur volatilia super terram, ex aquis tamen originem ducunt. Iudicat etiam spiritalis approbando, quod rectum, inprobando autem, quod perperam invenerit in operibus moribusque fidelium, elemosynis tamquam terra fructifera, et de anima viva mansuefactis affectionibus, in castitate, in ieiuniis, in cogitationibus piis, de his, quae per sensum corporis percipiuntur. De his enim iudicare nunc dicitur, in quibus et potestatem corrigendi habet. Vgl. ders., De inmortalitate animae 3, 3, ed. Hörmann 103-105.

${ }^{101}$ Lacan, Seminar 7, 148-156.

${ }^{102}$ Michel Foucault, Die Ordnung der Dinge (Frankfurt am Main 1971) 91-103; Julia Kristeva, Powers of Horror. An Essay on Abjection (European Perspectives: A Series in Social Thought and Cultural Criticism, Columbia University Press 1982); [dt. Übers.: Die Mächte des Grauens. Versuch über den Abscheu (Frankfurt am Main 1998)]; Lacan, Seminar 2, 406.
} 
